University of Nebraska - Lincoln

DigitalCommons@University of Nebraska - Lincoln

2022

\title{
Modeling the evolution of herbicide resistance in weed species with a complex life cycle
}

\author{
K. Harrison Holmes \\ John L. Lindquist \\ Richard Rebarber \\ Rodrigo Werle \\ Melinda K. Yerka
}

See next page for additional authors

Follow this and additional works at: https://digitalcommons.unl.edu/bioscitenhumberg

Part of the Agriculture Commons, Agronomy and Crop Sciences Commons, Genetics and Genomics Commons, and the Weed Science Commons

This Article is brought to you for free and open access by the Papers in the Biological Sciences at DigitalCommons@University of Nebraska - Lincoln. It has been accepted for inclusion in Brigitte Tenhumberg Papers by an authorized administrator of DigitalCommons@University of Nebraska - Lincoln. 


\section{Authors}

K. Harrison Holmes, John L. Lindquist, Richard Rebarber, Rodrigo Werle, Melinda K. Yerka, and Brigitte Tenhumberg 


\title{
Modeling the evolution of herbicide resistance in weed species with a complex life cycle
}

\author{
K. Harrison Holmes, ${ }^{1}$ John L. Lindquist, ${ }^{2}$ Richard Rebarber, ${ }^{1}$ \\ Rodrigo Werle, ${ }^{3}$ Melinda Yerka, ${ }^{4}$ and Brigitte Tenhumberg ${ }^{5}$
}

1 Department of Mathematics, University of Nebraska-Lincoln, Lincoln, Nebraska 68588

2 Department of Agronomy and Horticulture, University of Nebraska-Lincoln, Lincoln, Nebraska 68588

3 Department of Agronomy, University of Wisconsin-Madison, Madison, Wisconsin 53706

4 Department of Agriculture, Nutrition and Veterinary Sciences, University of Nevada-Reno, Reno, Nevada 89557

5 School of Biological Sciences and Department of Mathematics, University of Nebraska-Lincoln, Lincoln, Nebraska 68588

Corresponding author — Brigitte Tenhumberg, email btenhumberg2@unl.edu

ORCID — Brigitte Tenhumberg, https://orcid.org/0000-0003-3801-3192

\begin{abstract}
A growing number of weed species have evolved resistance to herbicides in recent years, which causes an immense financial burden to farmers. An increasingly popular method of weed control is the adoption of crops that are resistant to specific herbicides, which allows farmers to apply the herbicide during the growing season without harming the crop. If such crops are planted in the presence of closely related weed
\end{abstract}

Published in Ecological Applications, 32:1 (2022), e02473.

doi:10.1002/eap.2473

Copyright (C) 2021 by the Ecological Society of America. Used by permission. Submitted 8 December 2020; revised 17 February 2021; accepted 21 April 2021; final submitted 27 September 2021; published 15 October 2021.

Citation: Holmes, K. H., J. L. Lindquist, R. Rebarber, R. Werle, M. Yerka, and B. Tenhumberg. 2022. Modeling the evolution of herbicide resistance in weed species with a complex life cycle. Ecological Applications 32(1):e02473. doi:10.1002/eap.2473 
species, it is possible that resistance genes could transfer from the crop species to feral populations of the wild species via gene flow and become stably introgressed under ongoing selective pressure by the herbicide. We use a density-dependent matrix model to evaluate the effect of planting such crops on the evolution of herbicide resistance under a range of management scenarios. Our model expands on previous simulation studies by considering weed species with a more complex life cycle (perennial, rhizomatous weed species), studying the effect of environmental variation in herbicide effectiveness, and evaluating the role of common simplifying genetic assumptions on resistance evolution. Our model predictions are qualitatively similar to previous modeling studies using species with a simpler life cycle, which is, crop rotation in combination with rotation of herbicide site of action effectively controls weed populations and slows the evolution of herbicide resistance. We find that ignoring the effect of environmental variation can lead to an over- or under-prediction of the speed of resistance evolution. The effect of environmental variation in herbicide effectiveness depends on the resistance allele frequency in the weed population at the beginning of the simulation. Finally, we find that degree of dominance and ploidy level have a much larger effect on the predicted speed of resistance evolution compared to the rate of gene flow.

Keywords: bud bank, crop rotation, gene flow, herbicide-resistant crop plants, matrix model, polyploidy, rhizomatous perennial weed

\section{Introduction}

Since the late 1960s, herbicides have become a valuable tool for farmers in the United States to reduce competition from weeds in agroecosystems (Gianessi and Reigner 2007). At the same time, the number of effective herbicide sites of action available to farmers is shrinking because many weed species have evolved resistance to the herbicide sites of action in use (Gould and Brown 2018). To date, over 262 cases of unique weed species with herbicide resistance across 71 countries have been recorded (Heap 2019). The development of herbicide resistance is problematic because no new herbicide sites of action have been discovered for over three decades (Reviewed by Duke 2012). This loss of control through resistance can double the economic costs of weed management (Hicks et al. 2018).

A reduced susceptibility of weeds to herbicides has contributed to an overall increase in herbicide applications (Schütte et al. 2017). Herbicide drift to field margins impacts biodiversity of agricultural landscapes, not only because field margins and hedgerows often harbor rare plant species (Schmitz and Schäfer 2014), but because they also sup-

port decomposers, predators, pollinators, and parasitoids. Another risk 
to biodiversity is the possibility of herbicide-resistant crop plants fertilizing weedy relatives, which is possible over relatively long distances. For example, a low level of hybridization between cultivated and wild radish was detected up to a distance of $1 \mathrm{~km}$ (Ellstrand 2001). Such gene flow can not only produce viable hybrids forming persistent populations outside cultivation but may also lead to novel combinations of transgenic forms in the wild (Schafer et al. 2011). Ecological consequences of hybridization between a crop and its wild relative include an increased extinction risk of the wild subspecies (Kiang and Antonovics 1979, Small 1984).

One important factor contributing to the rise in weed herbicide resistance is the adoption of crops that are resistant to specific herbicides, particularly glyphosate in maize, cotton, canola, soybean, sugar beet, and alfalfa (Brookes and Barfoot 2017). The herbicide resistance traits are generally incorporated into crop plants through genetic engineering. However, it is also possible to create herbicide-resistant crops through traditional breeding methods (Werle et al. 2017b). One consequence of using this technology is a change in the herbicide use profile (Brookes and Barfoot 2017). Farmers used to apply a broad range of mostly selective herbicides targeting grass and/or broad-leaved weed species. After the adoption of herbicide-resistant crop plants such as Roundup Ready (glyphosphate-resistant) crops, many farmers relied heavily on single broad-spectrum herbicides. This approach imposed an enormous selective pressure on weed species and contributed to the evolution of weed populations consisting of a large proportion of resistant individuals (Brookes and Barfoot 2017). Federal regulatory agencies and practitioners are concerned about the cultivation of herbicide-resistant crops in regions where wild relatives are present, as crop-wild gene flow could speed the evolution of herbicide-resistant weeds (Ridley and Alexander 2016). Such is the case with the sorghum crop-wild complex in the United States and much of the world. Cultivated sorghum (S. bicolor (L.) Moench] is under major international development as a food, feed, and biofuel crop because it typically requires less water and fertilizer than maize (Zea mays L.), but its use is limited by the difficulty of controlling grass weeds post-emergence (Mace 2013, Schlegel et al. 2016).

A large body of simulation studies have been developed to predict the evolution of herbicide resistance in annual weed populations under different management scenarios (Neve et al. 2011a, Renton et al. 2011, 
2014, Bagavathiannan et al. 2013, 2014, Liu et al. 2017, Somerville et al. 2017, Werle et al. 2017b, Evans et al. 2018, b). One key management strategy included in these studies is crop rotation, where farmers grow a sequence of crops consecutively on the same field. Crop rotation may diversify selection pressures because each crop species in the rotation requires the use of different herbicides and timing of applications, and, consequently, the evolution of resistance to single modes of action is delayed (Neve 2008, Norsworthy 2012). The results of these simulation studies suggest that crop rotation combined with herbicide rotation effectively slows the evolution of weed herbicide resistance. Here we will expand on this literature in three important ways by considering more complex weed life cycles, environmental variation in herbicide effectiveness, and a range of different genetic assumptions about the crop and weed species of interest. Results of this analysis will be useful to risk assessments of new herbicide resistance traits by federal regulatory agencies where crop-wild gene flow is a concern.

\section{Complex life cycle}

When predicting evolutionary outcomes, it is important to consider the life history of organisms. Generally it has been assumed that the evolutionary change is slower in species with overlapping generations compared to species with non-overlapping generations (Templeton and Levin 1979, Hairston and De Stasio 1988, Venable 1989) because the removal rate from the pool of genotypes stored in long lived life history stages is slow. Additionally, if the fitness of different phenotypes in the population varies over time (temporally fluctuating selection) and selection is stage-specific then, theoretically, temporally fluctuating selection can contribute to maintaining genetic variation even in the absence of a heterozygote advantage in species with overlapping generations (Ellner and Hairston 1994) but not in species with non-overlapping generations (Lande 1977, Turelli 1988, Barton and Turelli 1989). Many weed species have overlapping generations. In annual weeds, the stage that serves as gene pool storage is the seedbank and in rhizomatous perennial weeds there is an additional storage stage, the bud bank. Herbicide applications do not affect seeds in the seed bank and have generally a lower impact on buds in the bud bank compared to aboveground stages. Hence, chemical weed management produces stage-specific selection 
and temporally varying selection due to crop rotation. Overall, we expect that the speed of herbicide resistance evolution is slower in rhizomatous perennial weeds compared to annual weeds with a seed bank.

As far as we know, past simulation studies have focused almost entirely on annual weed populations, which may not adequately represent the evolutionary dynamics of perennial species (but see Liu et al. 2019). This is problematic because a significant number of economically important weed species are perennial plants such as field bindweed (Convolvulus arvensis; Holm et al. 1977), Johnsongrass (Sorghum halepense; DeFelice 2006), quackgrass (Elymus repens; Melander 1994), and nutsedge spp. (Holm et al. 1977). Johnsongrass is of particular concern given that it can interbreed with grain sorghum, a widely cultivated grain crop species. In this manuscript, we expand the model developed by Werle et al. (2017a) to evaluate key differences (if any) in management strategies predicted to slow the evolution of herbicide resistance in annual and rhizomatous perennial weed species in the presence of gene flow between crops and weed relatives. Including gene flow is important because 12 of the world's 13 most important crops interbreed with wild relatives in some part of their agricultural distribution (reviewed by Ellstrand and Prentice [1999]), and most simulation studies do not account for gene flow from herbicide resistant crop plants to weedy relatives growing in the same field (but see Werle et al. 2017a).

\section{Variation in herbicide effectiveness}

Recent theoretical developments suggests that evolutionary trajectories are influenced by environmental variation (reviewed in Sæther and Steiner 2015). The reason why environmental variation matters is because it determines what quantities evolution maximizes. In the absence of variation, evolution will maximize mean fitness, while in fluctuating environments evolution maximizes geometric mean fitness (Sæther and Steiner 2015). The more similar the different phenotypes in a population respond to environmental variation the faster the speed of evolution (Lande 2007). Hence, the distribution of phenotypic responses to environmental variation determines evolutionary trajectories through time and implies that environmental variation induces frequency-dependent selection (Heino and Metz 1998, Lande and Steinar 2009). With respect to herbicide resistance evolution, the arguably most important 
environmental factor determining weed fitness is variation in herbicide effectiveness producing variation in selection intensity. If plants in the population vary in the number of resistance alleles and hence differ in their survival of herbicide applications, frequency-dependent selection is possible, implying that the frequency of resistance alleles in the population prior to the introduction of a particular herbicide may influence evolutionary trajectories.

In Fig. 1, we illustrate possible effects of environmental variation on predicting the speed of resistance evolution. We use the nonlinear function $f$ proposed by Roughgarden (1998) to map resistance allele frequencies $\rho$ ranging from 0 to 1 to expected allele frequencies in the next generation, assuming complete dominant inheritance involving one gene with two alleles. Assume that there is a $50 \%$ chance of high herbicide effectiveness (low fitness) and 50\% chance of a low herbicide effectiveness (high fitness). The first case produces allele frequency $\rho_{1}$ and the second case allele frequency $\rho_{2}$. The correct way to calculate the expected average allele frequency in the following year is $\left(f\left(\rho_{1}\right)+f\left(\rho_{2}\right)\right) / 2$. If you ignore the variation in herbicide effectiveness by assuming it is always the average of high and low effectiveness, then you only consider allele frequency $\bar{\rho}=\left(\rho_{1}+\rho_{2}\right) / 2$ to predict the allele frequency in the following year $f(\bar{\rho})$. Whether ignoring this variation results in an over- or underprediction of the speed of resistance evolution depends on how common the resistance allele is in the population. If allele frequencies are small (Fig. 1A), then $\left.f(\bar{\rho})>f\left(\rho_{1}\right)+f\left(\rho_{2}\right)\right) / 2$, which suggests that ignoring variation leads to over-predicting the speed of resistance evolution, but if allele frequencies are large (Fig. 1B) the opposite is the case. The over-prediction is a result of the function $f$ being convex down for small allele frequencies, and the under-prediction is a result of $f$ being convex up for large frequencies (Jensen's inequality 1906).

The effect of Jensen's inequality on resistance evolution depends on the shape of $f$, which is likely influenced by a variety of factors such as the relative performance of the different genotypes, ploidy level, density dependence, and weed-management strategies. As far as we know, it has not been previously demonstrated how between-year variation in herbicide effectiveness affects the speed of herbicide-resistance evolution. This gap in the literature is important as evidence accumulates that herbicide efficacy depends on environmental variables such as temperature during the growing season (Godar et al. 2015), ostensibly resulting 


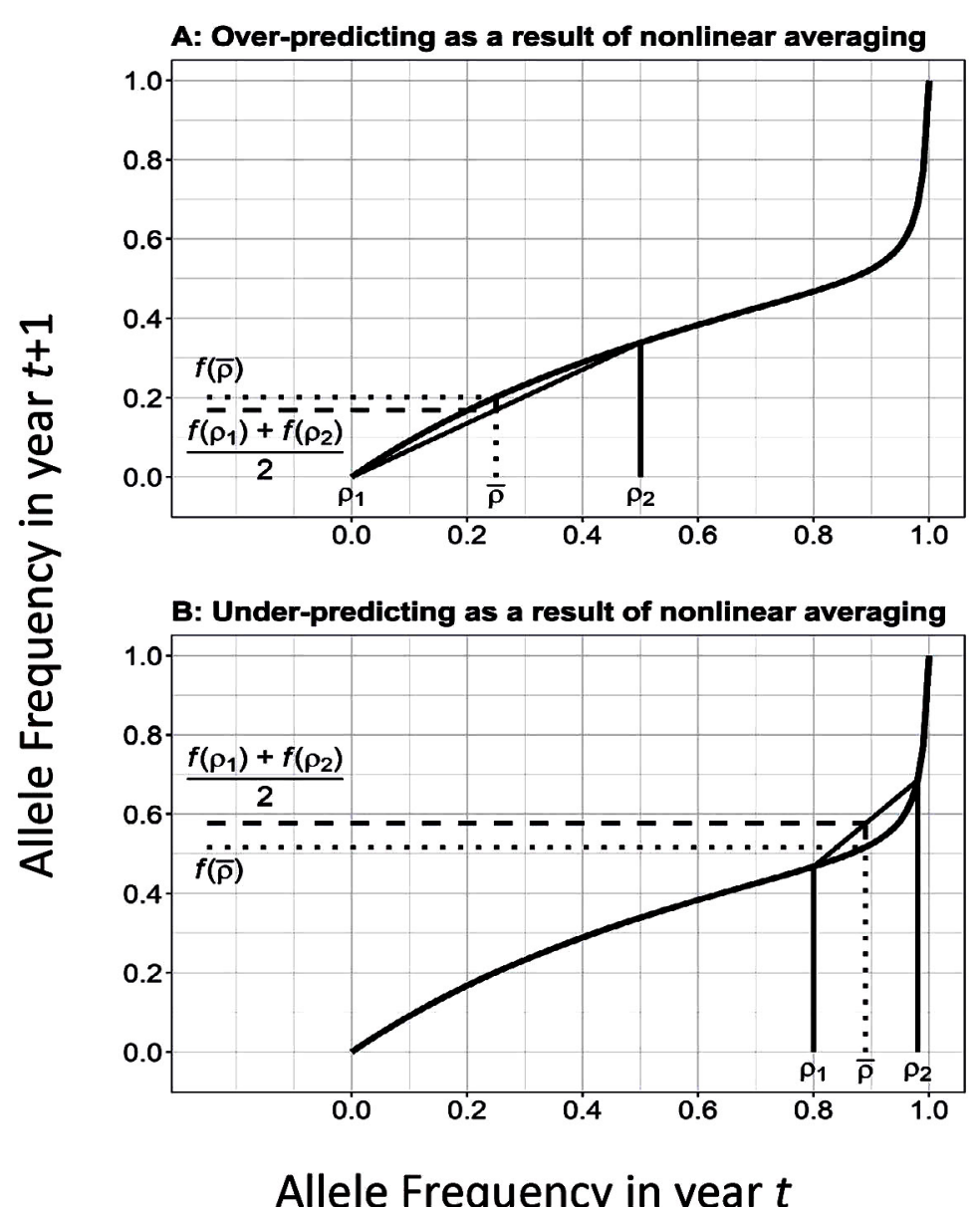

Fig. 1. Hypothesized effect of nonlinear averaging (Jensen's Inequality) on evolutionary dynamics. Specifically, the curve predicts how the frequency of resistance alleles $\rho$ changes from one generation to the next assuming resistance is inherited as a completely dominant gene with two alleles ( $A$ and $a$ ). Let $w_{a a}$ be the fitness of the homozygous susceptible, $w_{A A}$ be the fitness of the homozygous resistant, $w_{A a}$ be the fitness of heterozygous genotype, and $w$ be the average fitness of the entire population, then according to Roughgarden (1998), the resistance allele frequency in the next generation is $\left(\rho^{2} w_{a a}\right) \rho(1-\rho) w_{a A} / \bar{w}$, where $\left.\left.\bar{w}=\rho^{2} w_{a a}\right) 2 \rho(1-\rho) w_{a A}\right)+(1-\rho)^{2} w_{A A}$. The figure illustrates that the effect of nonlinear averaging depends on how common the resistance allele is in the population. This suggests that ignoring environmental variation (using $f(\bar{\rho})$ ) leads to $(\mathrm{A})$ over-predicting the speed of resistance evolution when the allele frequency in the population is relatively small $\left.\left(f(\bar{\rho})>f\left(\rho_{1}\right)+f\left(\rho_{2}\right) / 2\right)\right)$, while (B) we expect the opposite when the allele frequency is relatively large $\left(f(\bar{\rho})<f\left(\rho_{1}\right)\right.$ $\left.+f\left(\rho_{2}\right) / 2\right)$. Model parameters: $w_{a a}=6, w_{a A}=w_{A A}=240$. 
in differing levels of selective pressure on herbicide-resistance alleles and crop-weed competitive outcomes over time. If environmental variation is shown to play a key role in modifying herbicide selective pressures on weed populations, it will be of critical importance to incorporate this information into models predicting rates of herbicide resistance allele fixation and gene flow.

\section{Genetic assumptions}

Simulation models often make simplifying assumptions concerning the underlying inheritance pattern of traits of interest. To our knowledge, all published herbicide resistance models assumed diploid organisms, and most of those assumed dominant alleles conferring resistance. However, $10-40 \%$ of angiosperm diversity consists of plant species with more than two paired sets of chromosomes (Otto and Whitton 2000, Wood et al. 2009). The ploidy level is likely to influence the speed of resistance evolution, but whether polyploids evolve faster or slower than diploids is unclear. On one hand, gene duplication may dilute the effect of new mutations (Stebbins 1971). On the other hand, recent theoretical work suggests that the effect of ploidy level on the speed of adaptation depends on the mode of reproduction and the dominance coefficients (Otto and Whitton 2000). In asexual populations, beneficial alleles in separate individuals cannot be recombined into the same genome, which hinders adaptation (Fisher 1930). The speed of adaptation in asexual populations increases with ploidy level but only if the beneficial alleles are partially dominant (Otto and Whitton 2000). In sexual populations with ample genetic mixing, beneficial mutations that occur in separate individuals can be brought together by recombination (Fisher 1930), in which case, the fixation probability of beneficial alleles is very high, and the speed of adaptation always increases with the level of ploidy even if the beneficial allele is recessive.

Previous theoretical work focused on dynamics of natural populations over evolutionary time where spontaneous beneficial mutations play a key role (Otto and Whitton 2000). In contrast, mutations conferring herbicide resistance are too rare to influence evolutionary trajectories over the relatively short time frame that is relevant to farmers or industry. For instance, the mutation rate for the target gene conferring resistance to the herbicide glyphosate is assumed to be $5 \times 10^{9}$ (Neve 
et al. 2011a). More relevant for short-term dynamics of herbicide resistance evolution is the effect of gene flow between crop and weed plants, which is why it is receiving increased attention (Ellstrand 2014).

In this manuscript, we develop a density-dependent stage-structured model for an $n$-ploid plant to explore the evolution of herbicide resistance under different crop and herbicide rotation strategies within a 25yr time frame. We consider crop rotation to be accompanied by herbicide rotation. The model includes four stages: a seed bank, a bud bank associated with rhizomes, sprouts that grow from buds, and seedlings germinating from seeds. We assume one weed species that is a close relative of one of the crop species included in the rotation to be present, and consequently in some years there is gene flow between crop and weed plants. This gene flow and simulated natural selection is the only way for the frequency of resistance alleles to increase in the population. We explore evolutionary trajectories assuming resistance alleles are either completely absent at the time the herbicide is applied for the first time or resistance alleles are already present in the population but rare. When constructing the model we had the system Johnsongrass (Sorghum halepense (L.) Pers.) ( $2 n=4 x=40)$ and grain sorghum (S. bicolor (L.) Moench) $(2 n=2 x=20)$ in mind; however, the model could be modified and applied to other weed-crop systems that have the potential to interbreed by changing model parameters. We explore how the speed of herbicide resistance evolution is influenced by (1) crop rotation, (2) random variation in herbicide effectiveness (selection intensity), and (3) genetic assumptions including ploidy level, the degree of dominance of the alleles conferring herbicide resistance, and the magnitude of gene flow.

\section{Methods}

\section{Biological system}

We chose the Johnsongrass and grain sorghum system for the following reasons: first, grain sorghum is an economically important crop species worldwide (DeFelice 2006) and Johnsongrass is a widespread, closely related, weedy relative of grain sorghum. Johnsongrass is a warm-season perennial plant in the grass family, Poaceae. It is native to the Mediterranean region, and was introduced to the United States in the early 
1800s (McWhorter 1971). By the turn of the 20th century, it was recognized as one of the six most damaging agricultural weeds in the United States (McWhorter 1989). Johnsongrass is currently ranked as both one of the five most common and one of the five most problematic weeds in grain sorghum production (Weed Science Society of America 2017). Furthermore, Johnsongrass is currently classified as one of the 11 biggest resistance threats to U.S. agricultural systems (Hartzler 2020). Johnsongrass reproduces from rhizomes and from seed. In established populations, asexual reproduction contributes the most to population growth, while new populations are typically established via seed spread (Holm et al. 1977). Nicosulfuron is one group of herbicides that is used to control Johnsongrass and other weedy sorghum species that inhibits the acetolactate synthase (ALS) enzyme. Corteva Agriscience (Wilmington, Delaware, USA) is in the process of commercially deploying sorghum (Inzen sorghum hybrids) that is tolerant to an ALS-inhibiting herbicide using traditional breeding technology (Werle et al. 2017a, Bowman et al. 2021). Hence, it is possible that Johnsongrass growing in sorghum fields will be regularly exposed to large amounts of sorghum pollen carrying the ALS-resistance trait.

Second, crosses between Johnsongrass and sorghum can be viable under controlled conditions and in the field (evidence is reviewed in Ohadi et al. [2017]), suggesting that gene flow between sorghum and Johnsongrass is plausible. Moreover, sorghum-specific alleles have been identified in wild Johnsongrass populations, indicating successful gene flow and introgression (Morrell et al. 2005). Johnsongrass is tetraploid, while grain sorghum is diploid. Their offspring range from triploid up to sevenploid (Ohadi et al. 2017). Despite the ploidy differences, a recent preliminary field study using a single sorghum genotype reported hybridization rates between $0.5 \%$ and $1 \%$ (Subramanian et al. 2020). The hybrids were mostly tetraploid and survived ALS herbicide applications. In our model, we only consider tetraploid offspring resulting from crosses between female Johnsongrass plants and male Inzen sorghum pollen. Including all possible ploidy levels of hybrid offspring would make the model very complex and increase parameter uncertainty because we have insufficient information on the effect of ploidy level on outcrossing rate and hybrid vital rates. Nevertheless, once such parameters become available in the literature, the model could be modified to account for these differences. 
All parameter values are provided in Appendix S1: Tables S1-S3. Farmers in the Midwest use crop rotation combined with herbicide rotation as a management tool for weed and pest control, including slowing the evolution of pesticide resistance. We quantify the effect of crop rotation on weed control by comparing different crop rotation strategies, from continuously planting Inzen sorghum $\left(\omega_{1}\right.$, Fig. $\left.2 \mathrm{~B}\right)$ to rotating between Inzen sorghum and conventional sorghum (ALS sensitive; $\omega_{2}$, Fig. $2 B$ ).

Since Inzen sorghum technology will become available in U.S. sorghum production areas, farmers may adopt the crop-rotation schemes $\omega_{3}-\omega_{6}$ displayed in Fig. 2B (Werle et al. 2017a). Two of those strategies $\left(\omega_{5}\right.$ and $\left.\omega_{6}\right)$ are typically adopted in regions with limited rainfall as a water conservation strategy (two crops in three years). In our model, we explore the effect of all strategies listed in Fig. 2B on Johnsongrass population size and speed of resistance evolution (Table 1).

Table 1. Definition of model parameters used in Fig. 2.

\begin{tabular}{lr}
\hline Vital rates associated with seeds (stage 1) & \\
$\quad$ Probability of seeds germinating & $\widetilde{g}_{1}$ \\
Seed production by seedlings & $f_{3,1}$ \\
Sprout production by seedlings & $f_{3,2}$ \\
Seed survival June-October & $s_{1 \mathrm{~J}}$ \\
Seed survival November-March & $s_{1 \mathrm{~N}}$ \\
Seed survival April-May & $s_{1 \mathrm{~A}}$ \\
$\quad$ Seed survival of post-dispersal seed predation & $s_{1 \mathrm{P}}$ \\
Vital rates associated with buds (stage 2) & $\widetilde{g}_{2}$ \\
Probability of sprouts sprouting & $f_{4,1}$ \\
Seed production by sprouts & $f_{4,2}$ \\
Sprout production by sprouts & $S_{2 \mathrm{~J}}$ \\
Bud survival June-October & $S_{2 \mathrm{~N}}$ \\
Bud survival November-March & $S_{2 \mathrm{~A}}$ \\
Bud survival April-May & \\
Vital rates associate with seedlings (stage 3) & $S_{3 \mathrm{~J}}$ \\
Seedling survival June-flowering & $s_{3 \mathrm{~A}}$ \\
Seedling survival April-May & \\
Vital rates associated with sprouts (stage 4) & $s_{4 \mathrm{~J}}$ \\
Sprout survival June-flowering & $s_{4 \mathrm{~A}}$ \\
Sprout survival April-May & $\sigma$ \\
Vital rates associated with herbicide applications & $\tau$ \\
Probability of emerging culms (seedlings and sprouts) surviving & \\
$\quad$ herbicide application & \\
Probability of buds in the soil surviving herbicide application &
\end{tabular}

Note: Parameter values and their estimation is described in Appendix S1. 


\section{Model description}

We developed a density-dependent, stage-structured, matrix model (Caswell 2001) with annual time steps to predict the evolution of herbicide resistance in a perennial weed species that reproduces via seeds and rhizomes. We assume resistance is inherited as a single gene, and is a completely dominant trait in diploid species, as previously shown to be the case with grain sorghum. The current model is an extension of the model by Werle et al. (2017b), which considers a diploid, annual, related, weed species that reproduces exclusively via seeds. The current expanded model considers vital rate estimates for spring (AprilMay), summer (June-October), and winter (November-March). We assume a population census is taken in June, after seeds have germinated and buds have sprouted, but before culms have flowered. Herbicides are applied post census. The herbicide mortality depends on plant genotype and which herbicide is applied in any given year. Our model simulates how the resistance gene frequency changes over time due to natural selection, and we refer to this as herbicide resistance evolution. Since we are interested in the effect of variation in selection intensity, our model introduces variation in the effectiveness of herbicide applications from year to year.

At its core, the model accounts for (1) weed demography, (2) genetic inheritance of the resistance trait, (3) and crop and weed management strategies. The model accounts for four Johnsongrass stages: viable seeds in the seed bank $(S)$, viable buds in the bud bank $(B)$, seedlings (aboveground plants produced by seeds; $O$ ), and sprouts (aboveground plants produced by buds; $Q$ ), which are much larger than seedlings. When the number of aboveground plant stages in year $t$ is combined, we let $P(t)=$ $O(t)+Q(t) \cdot P(t)$ refers to distinct culms rather than biologically distinct organisms. Because the probability that an aboveground plant flowers and is successfully pollinated (either by selfing or outcrossing) is close to 1 , we will not include possible contributions from culms that do not flower or have not been successfully pollinated. The transitions to the different Johnsongrass stages are illustrated in Fig. 2, and the parameters and their values are listed in Appendix S1: Tables S1 and S3. To make the notation for survival probability $s$ more intuitive, we use subscripts including plant stage and time period as follows: seed bank, 1 ; bud bank, 2; seedlings, 3; sprouts, 4; April-May, A; June-October, J; and 
November-March, N. Additionally we use $P$ to indicate surviving predation. For instance, seed survival from June to October is $s_{1 j}$, and seed survival of post dispersal seed predation is $s_{1 \mathrm{P}}$. The subscripts for fecundity use the same stage abbreviations to indicate which stage reproduces and whether they contribute to the seed bank or bud bank. For instance, the number of seeds produced by seedlings is $f_{3,1}$. Parameters $\sigma_{k}(t)$ and $\tau_{k}(t)$ indicate the probability of culms (seedlings and sprouts) and buds surviving herbicide application, respectively. Survival of herbicide application depends on the herbicide type used in any given year $t$ and, during Inzen years, survival probability also depends on the genotype (number of resistance alleles $k$ ). For brevity we use the simplified notation $\sigma$ and $\tau$ in this section.

In the following, we describe all possible transitions; the numbers in brackets indicate the associated transitions in Fig. 2A.

Seedbank, $S$.-Seeds in the seed bank survive from June to March with probability $s_{1 \mathrm{~J}} \times s_{1 \mathrm{~N}^{*}}$ (1) The proportion $\left(1-\widetilde{g}_{1}\right)$ of the surviving seeds that do not germinate survive the spring (April-May) in the seed bank with probability $s_{1 A^{*}}$ (2) The rest of the surviving seeds germinate with probability $\widetilde{g}_{1}$ and the emerging seedlings survive the spring with probability $S_{3 \mathrm{~A}}$.

Seedlings, $0 .-$ Seedlings survive the summer with probability $s_{1 \mathrm{~J}}$ and herbicide application with probability $\sigma$. Surviving seedlings flower and produce $f_{3,1}$ viable seeds. Those seeds that are neither consumed by seed predators $s_{1 \mathrm{P}}$ nor die during the winter $s_{1 \mathrm{~N}}$ may or may not germinate in the spring. (3) Seeds that do not germinate $\left(1-\widetilde{g}_{1}\right)$ and survive the spring in the soil $s_{1 \mathrm{~A}}$ enter the seed bank. (4) Seeds germinate with probability $\widetilde{g}_{1}$ and the emerging seedlings survive the spring until population census with probability $s_{3 \mathrm{~A}}$. After flowering, some of the seedlings also produce $f_{3,2}$ buds and the newly produced buds survive the winter with probability $s_{2 \mathrm{~N}}$. In the spring, the surviving buds either (5) enter the bud bank with probability $\left(1-\widetilde{g}_{2}\right) \times s_{2 A}$ or (6) join the population of sprouts with probability $\widetilde{g}_{2} \times S_{4 \mathrm{~A}}$.

Sprouts, Q.-Sprouts survive the summer with probability $S_{4 \mathrm{~J}}$ and herbicide application with probability $\sigma$. Surviving sprouts flower and produce $f_{4,1}$ viable seeds. Those seeds that are neither consumed by seed 
Fig. 2. (A) Life cycle graph of the Johnsongrass model and (B) crop rotations strategies $\omega_{1}-\omega_{6}$. In the life cycle graph the arrow indicate transitions (1)-(12) between the different plant stages from June in year $t$ to June in year $t+1$. All model parameters are listed in Table 1 . The probability of seeds germinating or sprouts sprouting is indicated by $\widetilde{g_{1}}$ and $\widetilde{g_{2}}$, respectively. Seedlings produce $f_{3,1}$ number of seeds and $f_{3,2}$ number of buds, while sprouts produce $f_{4,1}$ number of seeds and $f_{4,2}$ number of buds. Survival probabilities are indicated by the subscripted letter s. The numbers in subscripts indicate the stage (1, seed bank; 2 , bud bank; 3 , seedling; 4 , sprout) and the letters indicate the time period (J, June-October; N, November-March; A, April-May). For seeds, there is an additional letter $P$ indicating whether seeds survive post dispersal seed predation. The parameters $\sigma$ and $\tau$ specify the probability of emerging culms (seedlings and sprouts) and buds in the soil surviving herbicide application, respectively. (B) A table showing $\sigma$ and $\tau$ associated with the different crops in the rotation, except for Inzen sorghum because the survival of acetolactate synthase (ALS) herbicide depends on Johnsongrass genotype (Eqs. 1 and 2). Herbicide survival varies between all years (see variances in Appendix S1: Table S3), but natural selection occurs only when Inzen sorghum is planted (gray color in B). Natural selection for ALS resistance influences every transition except the transitions from seed bank to seed bank (1) and seedling to seed bank (3). PRE and POST indicates whether the herbicide is sprayed before or after emergence of the crop. This affects the values of $\sigma$ and $\tau$ but not the model implementation, since vital rates are multiplied to calculate transitions between plant stages. ALS, nicosulfuron; C, clethodim; Gly, glyphosphate.

predators $s_{1 \mathrm{P}}$ nor die during the winter $s_{1 \mathrm{~N}}$ may or may not germinate in the spring. (7) Seeds that do not germinate $\left(1-\widetilde{g}_{1}\right)$ and survive the spring in the soil $s_{1 \mathrm{~A}}$ enter the seed bank. (8) Seeds germinate with probability $\widetilde{g}_{1}$ and the emerging seedlings survive the spring until population census with probability $s_{3 \mathrm{~A}}$. After flowering, some of the sprouts also produce $f_{4,2}$ buds and the newly produced buds survive the winter with probability $s_{2 \mathrm{~N}}$. In the spring, the surviving buds either either (9) enter the bud bank with probability $\left(1-\widetilde{g}_{2}\right) \times s_{2 \mathrm{~A}}$ or $(10)$ join the population of sprouts with probability $\widetilde{g}_{2} \times S_{4 \mathrm{~A}}$.

Budbank, B.-Buds in the bud bank survive from June to March with probability $S_{2 \mathrm{~J} \times} S_{2 \mathrm{~N}}$ and herbicide application with probability $\tau$. (11) The proportion $\left(1-\widetilde{g}_{2}\right)$ of the surviving buds that do not sprout survive the spring (April-May) in the bud bank with probability $s_{2 A^{*}}$ (12) The rest of the surviving buds sprout with probability $\widetilde{g}_{2}$ and the emerging sprouts survive the spring with probability $S_{4 \mathrm{~A}}$. 
A

(1) Seeds do not germinate and survive in seed bank

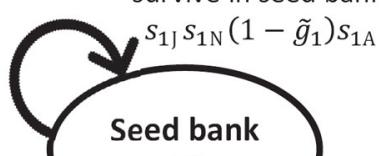

(S)
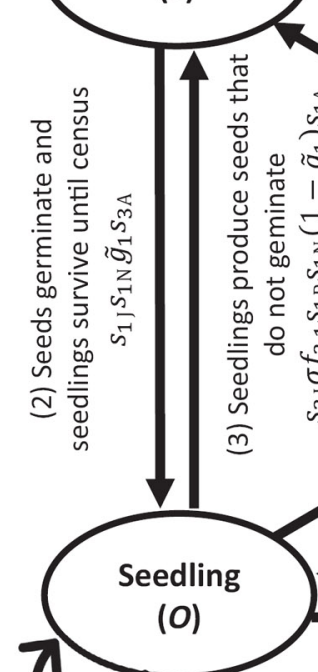

入

(4) Seedlings produce seeds that germinate

$s_{3 \mathrm{~J}} \sigma f_{3,1} s_{1 \mathrm{P}} s_{1 \mathrm{~N}} \tilde{g}_{1} s_{3 \mathrm{~A}}$

B

\begin{tabular}{|c|c|c|c|}
\hline \multirow{2}{*}{$\omega_{1}$} & Inzen sorghum & Inzen sorghum & Inzen sorghum \\
\cline { 2 - 4 } & ALS & ALS & ALS \\
\hline
\end{tabular}

\begin{tabular}{|c|c|l|c|}
\hline \multirow{2}{*}{$\omega_{2}$} & Inzen sorghum & Conv. sorghum & Inzen sorghum \\
\cline { 2 - 4 } & ALS & Pre Gly & ALS \\
& & $\sigma=0.4$ & \\
& & $\tau=0.4$ & \\
\hline
\end{tabular}

\begin{tabular}{|c|c|c|c|}
\hline \multirow{2}{*}{$\omega_{3}$} & Inzen sorghum & Soybean & Inzen sorghum \\
\cline { 2 - 4 } & ALS & Post Gly+C & ALS \\
& & $\sigma=0.01$ & \\
& & $\tau=0.04$ & \\
\hline
\end{tabular}

\begin{tabular}{|c|c|c|c|c|c|}
\hline \multirow{2}{*}{$\omega_{4}$} & Inzen sorghum & Soybean & Conv. sorghum & Soybean & Inzen sorghum \\
\cline { 2 - 6 } & ALS & Post Gly+C & Pre Gly & Post Gly+C & ALS \\
& & $\sigma=0.01$ & $\sigma=0.4$ & $\sigma=0.01$ & \\
& & $\tau=0.04$ & $\tau=0.4$ & $\tau=0.04$ & \\
\hline
\end{tabular}

\begin{tabular}{|c|c|c|c|c|}
\hline \multirow{2}{*}{$\omega_{5}$} & Inzen sorghum & No crop & Wheat & Inzen sorghum \\
\cline { 2 - 5 } & ALS & Pre Gly & Pre Gly & ALS \\
& & $\sigma=0.005$ & $\sigma=0.4$ & \\
& & $\tau=0.01$ & $\tau=0.4$ & \\
\hline
\end{tabular}

\begin{tabular}{|c|c|c|c|c|c|c|c|}
\hline \multirow{2}{*}{$\omega_{6}$} & Inzen sorghum & No crop & Wheat & Conv. sorghum & No crop & Wheat & Inzen sorghum \\
\cline { 2 - 7 } & ALS & Pre Gly & Pre Gly & Pre Gly & Pre Gly & Pre Gly & ALS \\
& & $\sigma=0.005$ & $\sigma=0.4$ & $\sigma=0.4$ & $\sigma=0.005$ & $\sigma=0.4$ & \\
& $\tau=0.01$ & $\tau=0.4$ & $\tau=0.4$ & $\tau=0.01$ & $\tau=0.4$ & \\
\hline
\end{tabular}

(11) Buds do not sprout and survive in bud bank $s_{2 \mathrm{~J}} \tau s_{2 \mathrm{~N}}\left(1-\tilde{g}_{2}\right) s_{2 \AA}$ Bud bank

(B)

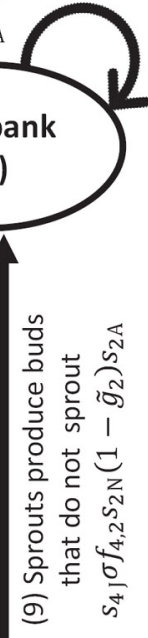

(8) Sprouts produce seeds that germinate

$$
s_{4 \mathrm{~J}} \sigma f_{4,1} s_{1 \mathrm{P}} s_{1 \mathrm{~N}} \widetilde{g}_{1} s_{3 \mathrm{~A}}
$$

(10) Sprouts produce buds that sprout $s_{4 \mathrm{~J}} \sigma f_{4,2} s_{2 \mathrm{~N}} \tilde{g}_{2} s_{4 \mathrm{~A}}$ 


\section{Genetics and inheritance of resistance}

The parameters $\sigma_{k}(t)$ and $\tau_{k}(t)$ specify the probability of culms and buds surviving herbicide applications, respectively. Herbicides differ in their control efficacy and which herbicide regime farmers use in any given year $t$ depends on the crop species planted. Hence, $\sigma_{k}(t)$ and $\tau_{k}(t)$ vary with crop species (see Fig. 2B with simplified notation). Nicosulfuron herbicide (ALS) is only applied in years when Inzen sorghum is planted and, in those years, the probability of culms and buds surviving an Inzen herbicide application depends on the genotype, i.e., the number of resistance alleles $k$. We assume that a single gene confers Inzen herbicide resistance, and denote the ALS-resistance allele with $R$ and the susceptible allele with $r$. This is consistent with previous observations of evolved ALS resistance among weedy Sorghum diploids indicating a predominantly single-gene, dominant, target-site mechanism (Preston and Mallory-Smith 2001), although instances of alternative mechanisms have been reported (Werle et al. 2017a). Inzen herbicide survival is calculated as follows:

$$
\begin{aligned}
& \sigma k(t)=\sigma k(t)\left(1-\left(\frac{k}{n}\right)^{e^{-h}}\right)+\left(\frac{k}{n}\right)^{e^{-h}} \\
& \tau k(t)=\tau k(t)\left(1-\left(\frac{k}{n}\right)^{e^{-h}}\right)+\left(\frac{k}{n}\right)^{e^{-h}}
\end{aligned}
$$

The parameter $h$ specifies the degree of dominance, which varies from $-\infty$ (recessive) to $+\infty$ (dominant), and $h \in(-\infty,+\infty)$ implies partial dominance of the resistance allele. The parameter $n$ specifies the ploidy level and $k$ the number of resistance alleles for a particular genotype where $k$ $\leq n$. Keeping track of the different genotypes implies that every life history stage has $n+1$ different genotypes. Since Johnsongrass is tetraploid ( $n=4$ and $k \in[0,4])$, our model includes 20 different stages ( 5 seed bank genotypes, 5 bud bank genotypes, 5 seedling genotypes, 5 sprout genotypes). We use $k$ as a subscript to denote the genotype of the different life history stages. For example, $B_{0}(t), B_{1}(t), B_{2}(t), B_{3}(t), B_{4}(t)$ specifies the number of individuals in the bud bank with $0,1,2,3,4$ resistance alleles out of $n=4$ total alleles that are present in year $t$. 


\section{Other survival parameters}

Seeds survive with probabilities $s_{1 \mathrm{~J}}, s_{1 \mathrm{~N}}, s_{1 \mathrm{~A}}$ over the periods June-October (summer), November-March (winter), and April-May (spring), respectively. Additionally, seeds can be consumed by seed predators before entering the seed bank. Seed predation in the seed bank is included in seed bank mortality. The probability of surviving seed predation is $S_{1 \mathrm{P}}$. Buds survive the spring and summer with probability $s_{2 \mathrm{~J}}$ and $s_{2 \mathrm{~A}}$, respectively. Since overwinter survival depends on plant age, our model considers that survival is higher in 1-yr-old buds $\left(s_{2 \mathrm{~N}_{1}}\right)$ compared to older buds $\left(s_{2 \mathrm{~N}_{2}}\right)$.

For seedlings and sprouts, we only consider spring and summer survival because all culms die off at the end of the growing season. Seedlings are generally much smaller than sprouts because there are fewer resources available in seeds compared to rhizomes and optimal temperature for bud sprout is lower than that for seed germination (Mitskas et al. 2003). As a consequence, seedlings are less likely to survive than sprouts since young plant survival generally increases with size (Tenhumberg et al. 2015). Spring survival is density dependent, which we implement using the self-thinning functions of Firbank and Watkinson (1985). Spring survival probabilities of seedlings $\left(s_{3 \mathrm{~A}}\right)$ and sprouts $\left(s_{4 \mathrm{~A}}\right)$ are calculated as follows:

$$
s_{3 \mathrm{~A}}(t)=\frac{1}{1+\alpha_{3 \mathrm{~A}}\left(O(t)+\delta_{3 \mathrm{~A}} Q(t)\right)}
$$

and

$$
S_{4 \mathrm{~A}}(t)=\frac{1}{1+\alpha_{4 \mathrm{~A}}\left(\delta_{4 \mathrm{~A}} O(t)+Q(t)\right)}
$$

where $O(t)$ and $Q(t)$ refer to all newly emerged seedlings and sprouts, respectively. Parameters $\left(\alpha_{3 \mathrm{~A}}\right)^{-1}$ and $\left(\alpha_{4 \mathrm{~A}}\right)^{-1}$ are maximum seedling and sprout density (no. $/ \mathrm{m}^{2}$ ), respectively, after self-thinning from very high seedling and sprout densities. Parameters $\delta_{3 \mathrm{~A}}$ and $\delta_{4 \mathrm{~A}}$ are competition coefficients representing the impact of seedlings on the survival of sprouts and the impact of sprouts on the survival of seedlings, respectively. We assumed that self-thinning occurs under high weed density during early stages of both weed and crop development. Since crop density is assumed to remain constant in this model regardless of weed density we did not account for it in Eq. 3. Crop density is accounted for in density 
dependent seed and bud production. After self-thinning occurs, culms from seedlings and sprouts survive the summer with probability $s_{3 \mathrm{~J}}$ and $S_{4 \mathrm{j}}$, respectively.

\section{Sexual and vegetative reproduction}

Seedlings and sprouts produce seeds as well as buds. Sprouts are larger and produce more seeds and buds compared to seedlings. We modeled per capita seed and bud production using a hyperbolic function of culm density (Firbank and Watkinson 1985, Renton et al. 2011, Werle et al. $2017 a$ ). We assume that competition is only exerted by culms that survive the early summer period, including herbicide application. Hence, the Johnsongrass density (no./ $\mathrm{m}^{2}$ ) affecting reproduction is

$$
P(t)=\sum_{k \in\{0,1, \ldots, 4\}}\left[\sigma_{k}(t)\left(s_{3 j} O_{k}(t)+s_{4\}} Q_{k}(t)\right)\right]
$$

which includes all $n+1$ genotypes in year $t$. The seed and bud production per culm is calculated as follows:

$$
f_{i j}=\frac{m_{i j} \kappa_{\mathrm{w}}}{1+\kappa_{\mathrm{w}} P(t)+\kappa_{\mathrm{c}} d_{\mathrm{c}}}
$$

where the subscript $i$ specifies which plant stage reproduces (seedlings, 3 or sprout, 4), and the subscript $j$ specifies the type of reproduction (seeds, 1 or buds, 2). So, $f_{i j}$ specifies the per capita seed production of seedlings $(i=3, j=1)$, the per capita bud production of seedlings ( $i=3$, $j=2)$, the per capita seed production of sprouts $(i=4, j=1)$, and the per capita bud production of sprouts $(i=4, j=2)$; $\kappa_{c}$ represents crop competitiveness, $\kappa_{\mathrm{w}}$ represents weed competitiveness, $d_{\mathrm{c}}$ represents crop density (plants $/ \mathrm{m}^{2}$ ), and $P(t)$ represents aboveground Johnsongrass culm density in year $t$ after herbicide application (culms $/ \mathrm{m}^{2}$ ).

\section{Mating and crop-to-weed gene flow}

Recall that we model Johnsongrass as a tetraploid, so $n=4$ in the following equations. We keep the equations general, as the model is designed to apply to a weed species of any ploidy level. Johnsongrass is self-compatible (Warwick and Black 1983), but we do not know to what extent 
Johnsongrass is selfing vs. crossing because as far as we know, there have not been any gene-flow studies conducted under field conditions among different accessions of Johnsongrass. Hence, as a starting point, we assume that zygotes (seeds) are derived from randomly mating gametes, and that the frequency of herbicide-resistance alleles changes according to the Hardy-Weinberg ratios. This is also consistent with other modeling studies simulating the effect of natural selection on gene frequencies (Roughgarden 1998).

All plants of a single genotype with $k$ number of resistance alleles that survive until flowering produce $\Psi_{k}(t)$ number of seeds in year $t$

$$
\Psi_{k}(t)=\sigma_{k}(t)\left(s_{3 \mathrm{~J}} f_{3,1}(t) O_{k}(t)+s_{4 \mathrm{~J}} f_{4,1}(t) Q_{k}(t)\right)
$$

where $f_{3,1}(t)$ and $f_{4,1}(t)$ indicate the number of seeds produced by each seedling and sprout, respectively; $O_{k}(t)$ and $Q_{k}(t)$ specify the number of seedlings and sprouts in the population, respectively; and $s_{3 \mathrm{~J}}$ and $s_{4 \mathrm{~J}}$ is the survival probability of seedlings and sprouts, respectively; $\sigma_{k}(t)$ indicates survival probability of the herbicide application. Hence, in year $t$, all seedlings and sprouts of the different genotypes that survive until flowering produce a total number of $\Sigma_{k \in\{0,1, \ldots, 4\}} \Psi_{k}(t)$ seeds.

The resistance allele frequency $(\rho)$ of the seeds produced by all five genotypes $(k \in\{0,1, \ldots, 4\})$ is calculated as follows:

$$
\rho(t)=\frac{\sum_{k \in\{0,1, \ldots, n\}} \Psi_{k}(t)(k / n) \Psi_{k}(t)}{\sum_{k \in\{0,1, \ldots, n\}} \Psi_{k}(t)}
$$

where the numerator is the sum of resistance alleles and the denominator is the pool of susceptible and resistance alleles.

Our model also considers pollen-mediated gene flow from grain sorghum to Johnsongrass plants. Following Werle et al. (2017b) we use Wright's Continent Island Model (Wright 1969) to calculate the effect of crop-to-weed gene flow on the resistance allele frequency in newly produced Johnsongrass seeds within the population of interest. Let $\gamma$ be the probability of gene transfer from the crop to Johnsongrass, then the gene frequency of Johnsongrass in the following year $t+1$ is

$$
\widetilde{p}(t+1)=\rho(t)(1-\gamma)+\gamma
$$


In our example, $\gamma=0$ for all crop plants other than Inzen sorghum. While it is possible that crop-to-weed gene flow also occurs from wildtype grain sorghum to Johnsongrass, it would not be expected to confer a resistant phenotype that would be selected upon during Inzen years of the crop rotation. We calculate the frequency of the resistance alleles in the entire population in year $t$ as follows:

$$
p(t)=\frac{\sum_{k \in\{0,1, \ldots, n\}}(k / n)\left(S_{k}(t)+B_{k}(t)+O_{k}(t)+Q_{k}(t)\right)}{\sum_{k \in\{0,1, \ldots, n\}}\left(S_{k}(t)+B_{k}(t)+O_{k}(t)+Q_{k}(t)\right)}
$$

where $k$ represents the number of resistance alleles of individuals in the four different stages. $S_{k}$ represents the number of seeds in the seed bank, $B_{k}$ indicates the number of buds in the bud bank, $O_{k}$ represents the number of seedlings, and $Q_{k}$ the number of sprouts. We begin our simulation either with zero resistant plants in the population or an initial resistant allele frequency of 0.0006 . In the first case, crop-to-weed gene flow is the initial source of resistance alleles in the Johnsongrass population. We include the latter case because resistance alleles have been documented in weed populations that predate herbicides (Délye et al. 2013).

\section{Development of matrix model structure}

Let $\mathbf{w}(t)$ be the population vector keeping track of the number of individuals in the 20 different life-history stages ( 5 genotypes $\times 4$ life history stages) in each year $t$

$$
\mathbf{w}(t)=\left[S_{4}, \ldots, S_{0}, B_{4}, \ldots, B_{0}, O_{4}, \ldots, O_{0}, Q_{4}, \ldots, Q_{0}\right](t)
$$

The aforementioned vital rates are included in different matrices described in detail in Appendix S1. They serve to calculate the transition of the genotypic distributions from one year to the next. We calculate the contributions to the different genotypes and plant stages from vegetative and sexual reproduction separately because only sexual reproduction changes allele frequency via mating. Plants that survive the summer and the application of herbicides $\left(M_{1}\right)$ produce buds $\left(F_{1}\right)$. If they survive the winter and spring, they either sprout or stay in the bud bank $\left(G_{1}\right)$, so the vegetative contribution to the population in the next time step is $G_{1} F_{1}(t) M_{1}(t) \mathbf{w}(t)$. Seedlings and sprouting plants that 
survive the summer and herbicide application $\left(M_{2}\right)$ flower and produce seeds $\left(F_{2}\right)$. The newly produced seeds $(W)$ are distributed among the different genotypes according to the Hardy-Weinberg-Ratios $(H)$. If the seeds survive seed predation and the winter, then they germinate in the spring and become seedlings, otherwise they are added to the seed bank, so the sexual contribution to the population in the next time step is $G_{2} H(t) W F_{2}(t) M_{2}(t) \mathbf{w}(t)$.

The population vector changes from one year to the next as follows:

$$
\mathbf{w}(t+1)=G_{1} F_{1}(t) M_{1}(t) \mathbf{w}(t)+G_{2} H(t) W F_{2}(t) M_{2}(t) \mathbf{w}(t)
$$

The full matrices are described in Appendix S4.

\section{Variation in herbicide effectiveness}

The proportion of weeds killed by herbicides depends on the quality (weed coverage at appropriate rates) and timing (weed size) of herbicide applications as well as environmental conditions such as temperature, humidity, and soil moisture. To simulate random variation in the survival of herbicide applications ( $\sigma$ and $\tau$ ) we drew random values from beta distributions corresponding to each parameter's mean and variance (Appendix S1: Table S3). We repeated these simulations 10,000 times to get predictions of median and $97.5 \%$ and $2.5 \%$ quantiles as estimates of the $95 \%$ confidence intervals for population size and frequency of resistance alleles in the population.

\section{Programming language}

$R$ version 3.5.1 was used for all statistical analysis and model simulation (R Core Team 2018).

\section{Results}

\section{Crop rotation}

Our model predicts that planting crop rotations combined with herbicide rotations reduces weed population size (Fig. 3). Weed population sizes are highest when Inzen sorghum is planted every year $\left(\omega_{1}\right)$ due to 

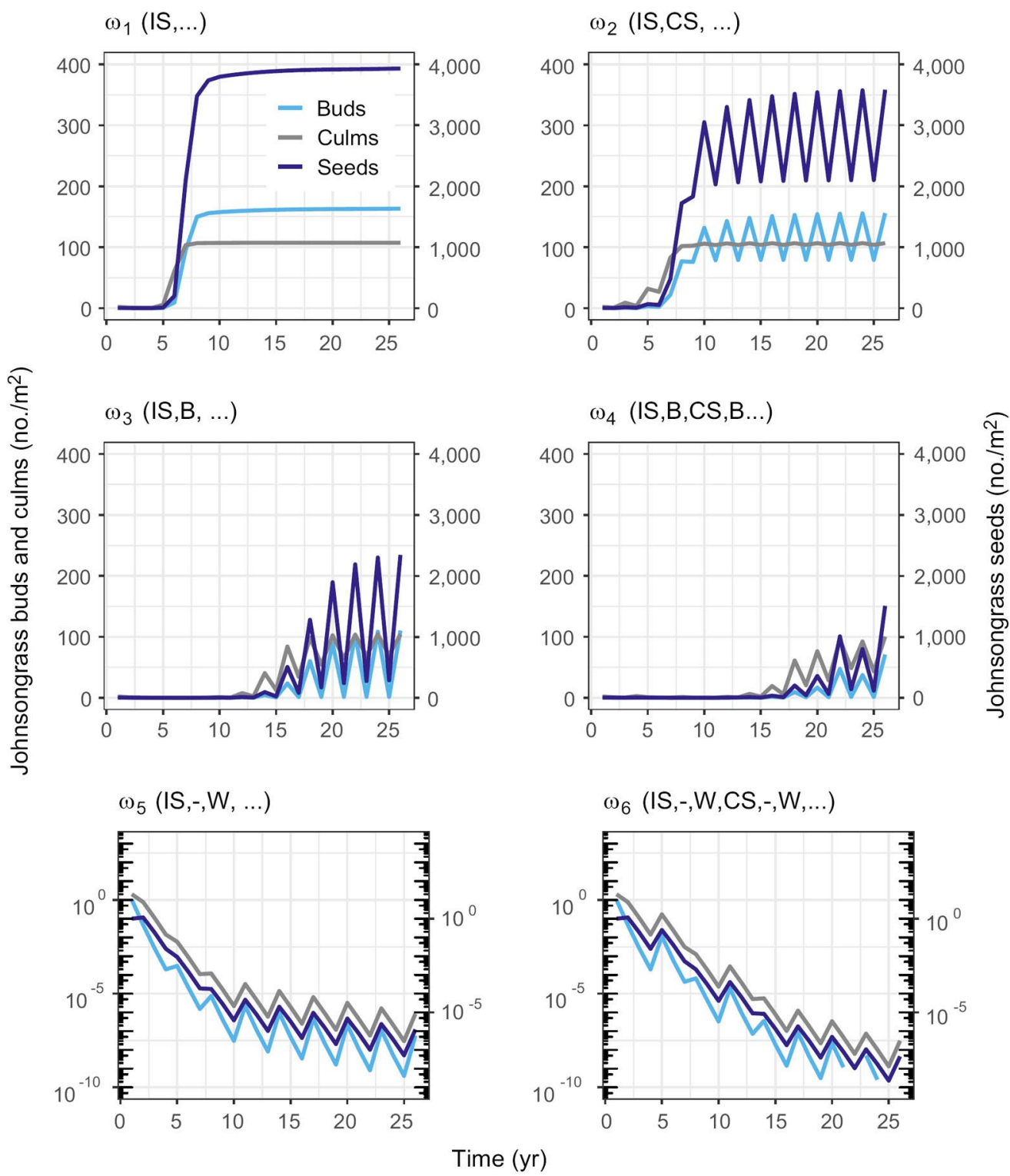

Fig. 3. Change in population size per $\mathrm{m}^{2}$ for different crop rotation strategies $\omega_{1-6}$ (Fig. 2B) over 25 simulation years. IS, Inzen sorghum; CS, conventional sorghum; B, soybean; -, no crop; W, wheat. Note that seed densities were an order of magnitude higher than the density of the other stages. To better visualize the trajectories of bud and culm densities we plotted seed densities on the right $y$-axis using a different scale.

increased survival of herbicide applications following introgressed resistance alleles from the crop. Rotation with conventional sorghum $\left(\omega_{2}\right)$ allows seed and bud densities to fluctuate, but culm densities asymptote to the same densities as when Inzen sorghum is planted every year. 


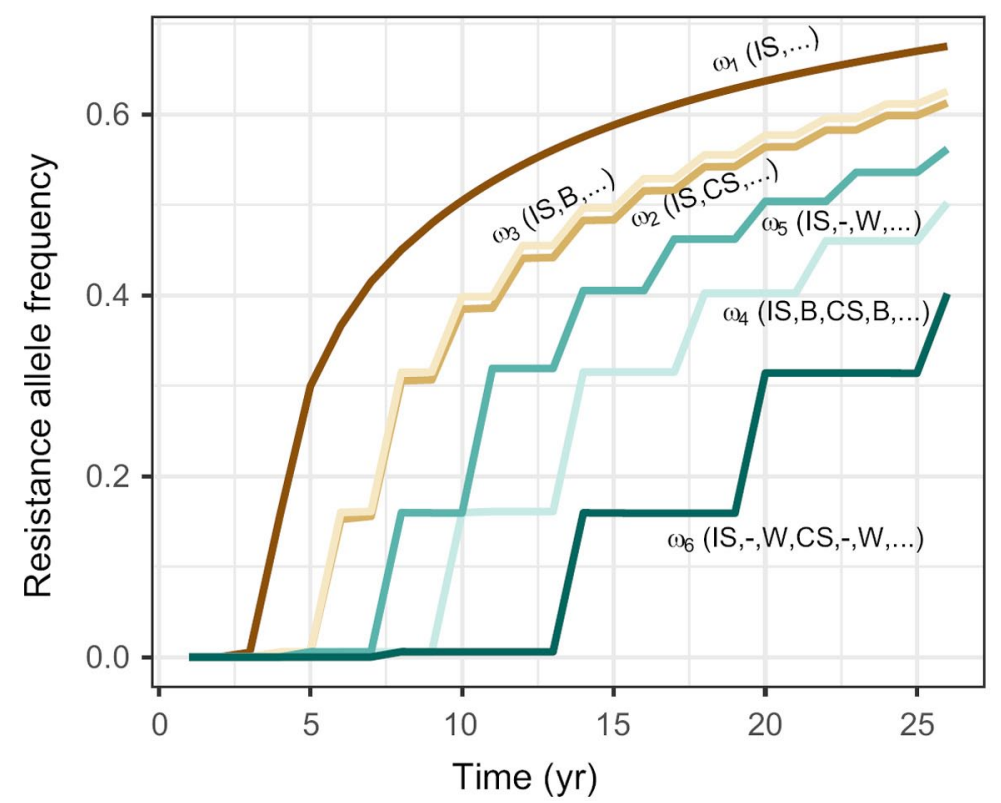

Fig. 4. Change in the proportion of resistance alleles $(p)$ for different crop rotation strategies $\omega_{1-6}$ (Fig. 2B) over 25 simulation years. IS, Inzen sorghum; CS, conventional sorghum; B, soybean; -, no crop; W, wheat. Note that, eventually, the proportion of gene frequency approaches 1 for all crop rotation strategies.

Incorporating soybean into the rotation $\left(\omega_{3}\right.$ and $\left.\omega_{4}\right)$ reduces population sizes even further and populations are driven to extinction if wheat and planting no crop for one season are introduced into the crop rotation $\left(\omega_{5}\right.$ and $\omega_{6}$ ). Note, in our modeling framework, plant densities can only approach zero but never reach zero. Further, our model predicts that the use of crop rotations combined with herbicide rotations slows the evolution of herbicide resistance (Fig. 4). Eventually, the proportion of resistance alleles in the population will go to fixation, but we only show the evolutionary trajectory over $25 \mathrm{yr}$ after planting Inzen sorghum for the first time and assuming the initial weed population is $100 \%$ susceptible to ALS-inhibiting herbicides. The more frequently Inzen sorghum is planted and the more frequent existing ALS-resistance alleles are in the population at this time, the faster the proportion of resistance alleles increases in the population. After 25 simulation years, allele frequency is highest in $\omega_{1}$ (Inzen every year), followed by $\omega_{2}$ and $\omega_{3}$ (Inzen every other year), followed by $\omega_{5}$ (Inzen every $3 \mathrm{yr}$ ), followed by $\omega_{4}$ (Inzen every $4 \mathrm{yr}$ ), and is lowest in $\omega_{6}$ (Inzen every $6 \mathrm{yr}$ ). 


\section{Variation in herbicide effectiveness}

In our model, we vary herbicide effectiveness across years. Our model predicts that the effect of variation in herbicide effectiveness depends on whether the weed population is $100 \%$ susceptible to ALS applications or not. If there are no resistance alleles in the population when Inzen is planted for the first time, variation slows resistance evolution (Fig. 5) for all crop rotation scenarios considered. However, if the initial gene frequency is 0.0006, then variation has the opposite effect (Fig. 6). The distribution of resistance allele frequency is highly skewed towards the upper bound of the $97.5 \%$ quantile and most values are as high as the median. The effect of variation on predicted median population size was independent of the initial allele frequency and always resulted in a lower median population size compared to the no-variation scenarios (Appendix S5: Figs. S1,S2).

\section{Genetic assumptions}

We only tested the effect of genetic assumptions (ploidy level, degree of dominance, gene flow) on the evolution of herbicide resistance for the worst case scenario when plants experience herbicide selection pressure every year when Inzen sorghum is grown continuously $\left(\omega_{1}\right)$. The qualitative effect of genetic assumptions are unlikely to change for different crop rotations because selection pressure is only applied during Inzen years, and there are no costs of resistance considered in this model that could have reversed selection during non-Inzen years.

Ploidy level.-We compared the rate of herbicide resistance evolution of a tetrapoid genotype (Johnsongrass) with a diploid genotype (assuming Johnsongrass would be diploid). We found that in diploid plants the frequency of resistance alleles increases faster compared to tetraploid plants (compare Fig. 7A with B and Fig. 7C with D).

Degree of dominance, $h$. - In our model, we assume herbicide resistance is conferred by a dominant gene ( $h=7$, Appendix S2: Fig. S1). If resistance alleles are intermediately dominant or dominant $(h \geq 0)$ then the speed of resistance evolution initially increases with increasing $h$ but after $5 \mathrm{yr}$ it reverses such that the speed decreases with increasing $h$ 
$\omega_{1}(\mathrm{IS}, \ldots)$

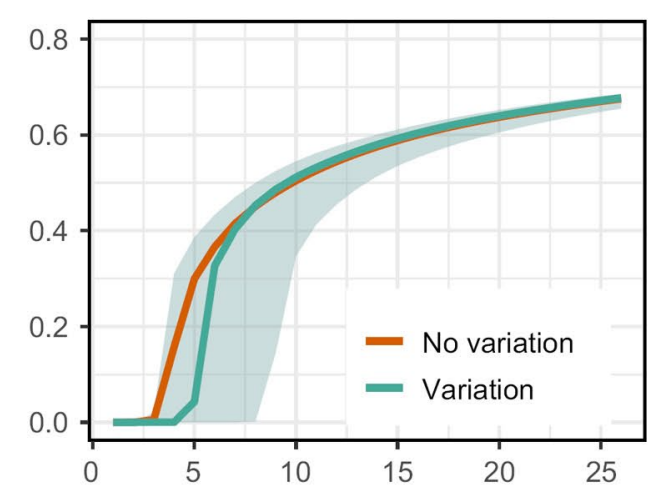

$\omega_{3}(\mathrm{IS}, \mathrm{B}, \ldots)$

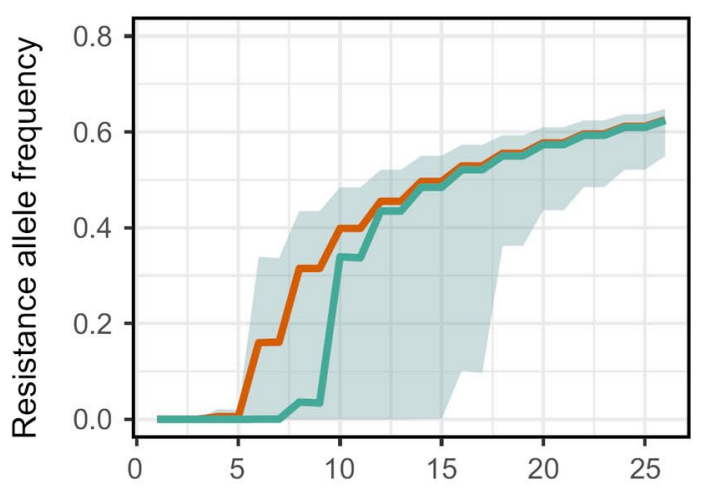

$\omega_{5}(\mathrm{IS},-, \mathrm{W}, \ldots)$

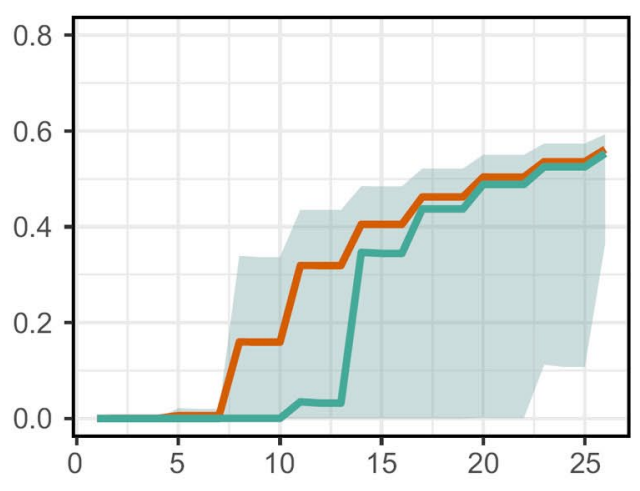

$\omega_{2}(\mathrm{IS}, \mathrm{CS}, \ldots)$

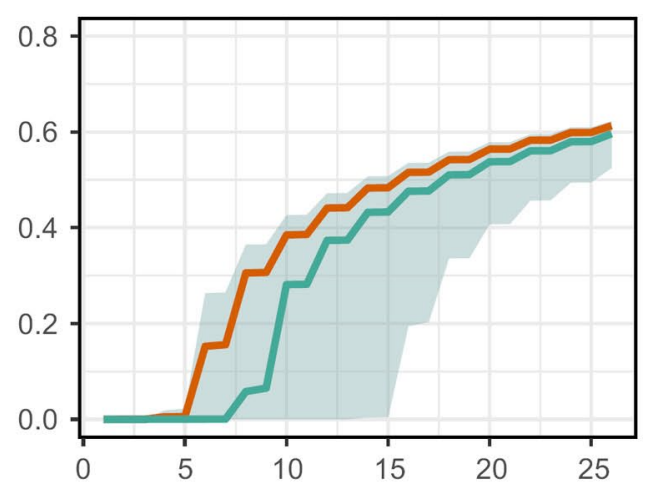

$\omega_{4}(\mathrm{IS}, \mathrm{B}, \mathrm{CS}, \mathrm{B} \ldots)$

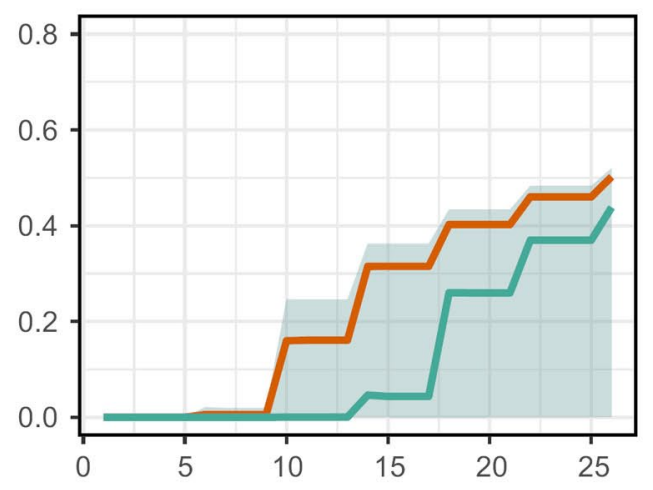

$\omega_{6}(\mathrm{IS},-, \mathrm{W}, \mathrm{CS},-, \mathrm{W}, \ldots)$

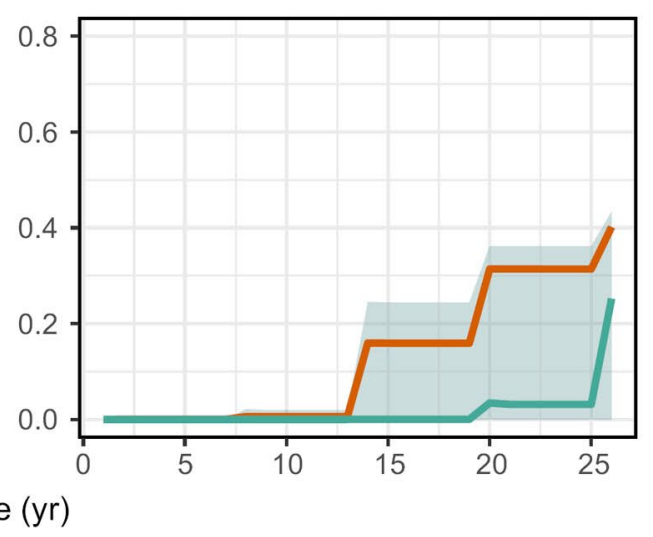

Fig. 5. Proportion of resistance alleles when herbicide effectiveness varies between years and the initial gene frequency is zero. The median is indicated by the solid green line and the shaded area represents the $95 \%$ confidence intervals. For comparison, we included the model predictions if herbicide effectiveness does not vary (solid orange line). The associated culm densities are displayed in Appendix S4: Fig. S1). 
$\omega_{1}(\mathrm{IS}, \ldots)$

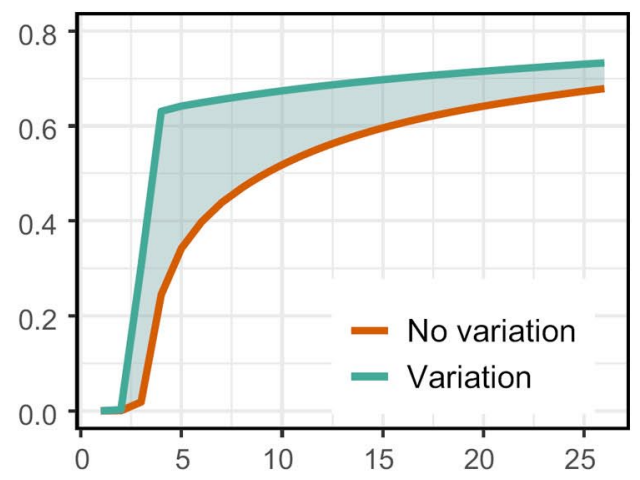

$\omega_{3}(\mathrm{IS}, \mathrm{B}, \ldots)$

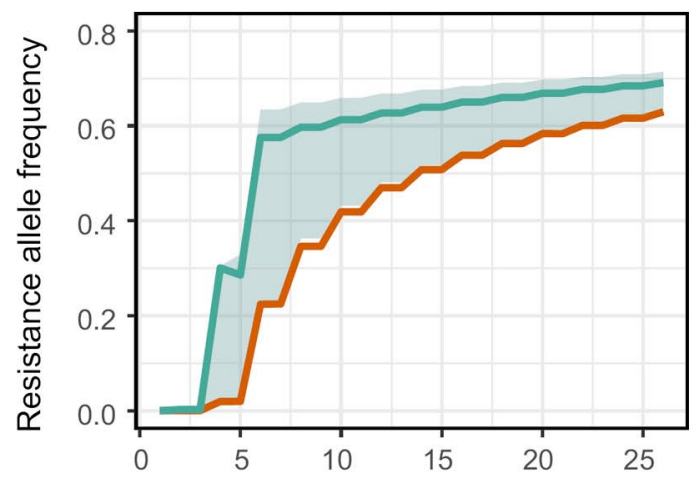

$\omega_{5}($ IS, $,-, W, \ldots)$

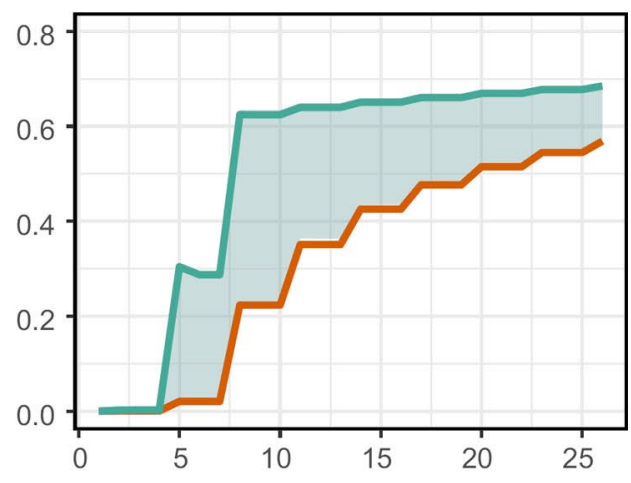

$\omega_{2}(\mathrm{IS}, \mathrm{CS}, \ldots)$

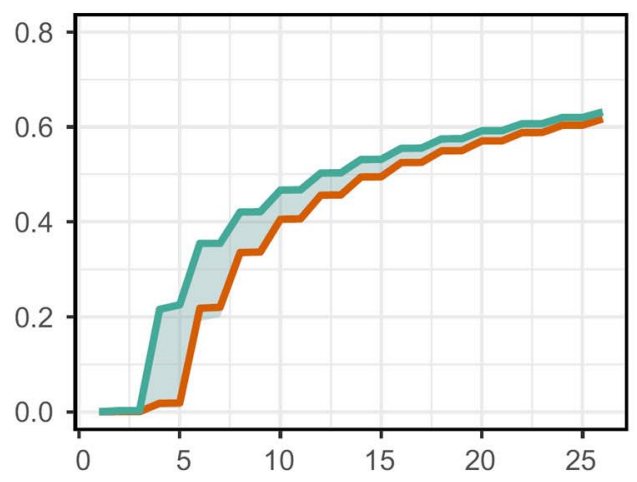

$\omega_{4}(\mathrm{IS}, \mathrm{B}, \mathrm{CS}, \mathrm{B} \ldots)$

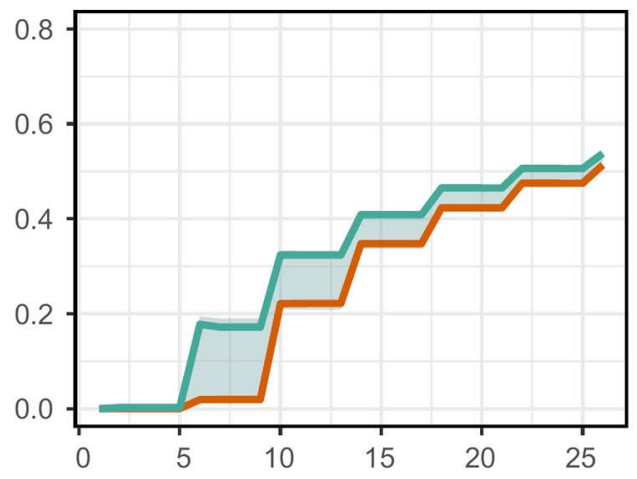

$\omega_{6}(\mathrm{IS},-, \mathrm{W}, \mathrm{CS},-, \mathrm{W}, \ldots)$

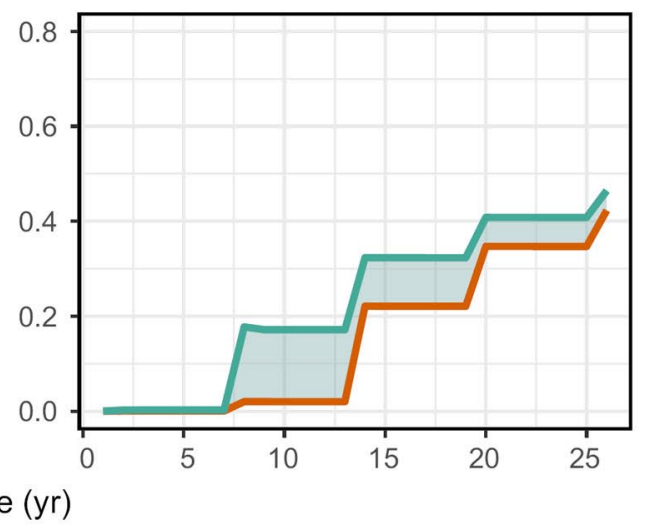

Fig. 6. Proportion of resistance alleles when herbicide effectiveness varies between years and the initial gene frequency is 0.0006 . The median is indicated by the solid green line and the shaded area represents the $95 \%$ confidence intervals. For comparison, we included the model predictions if herbicide effectiveness does not vary (solid orange line). The associated culm densities are displayed in Appendix S4: Fig. S2). 
Diploid plants

A) Degree of dominance, $h$
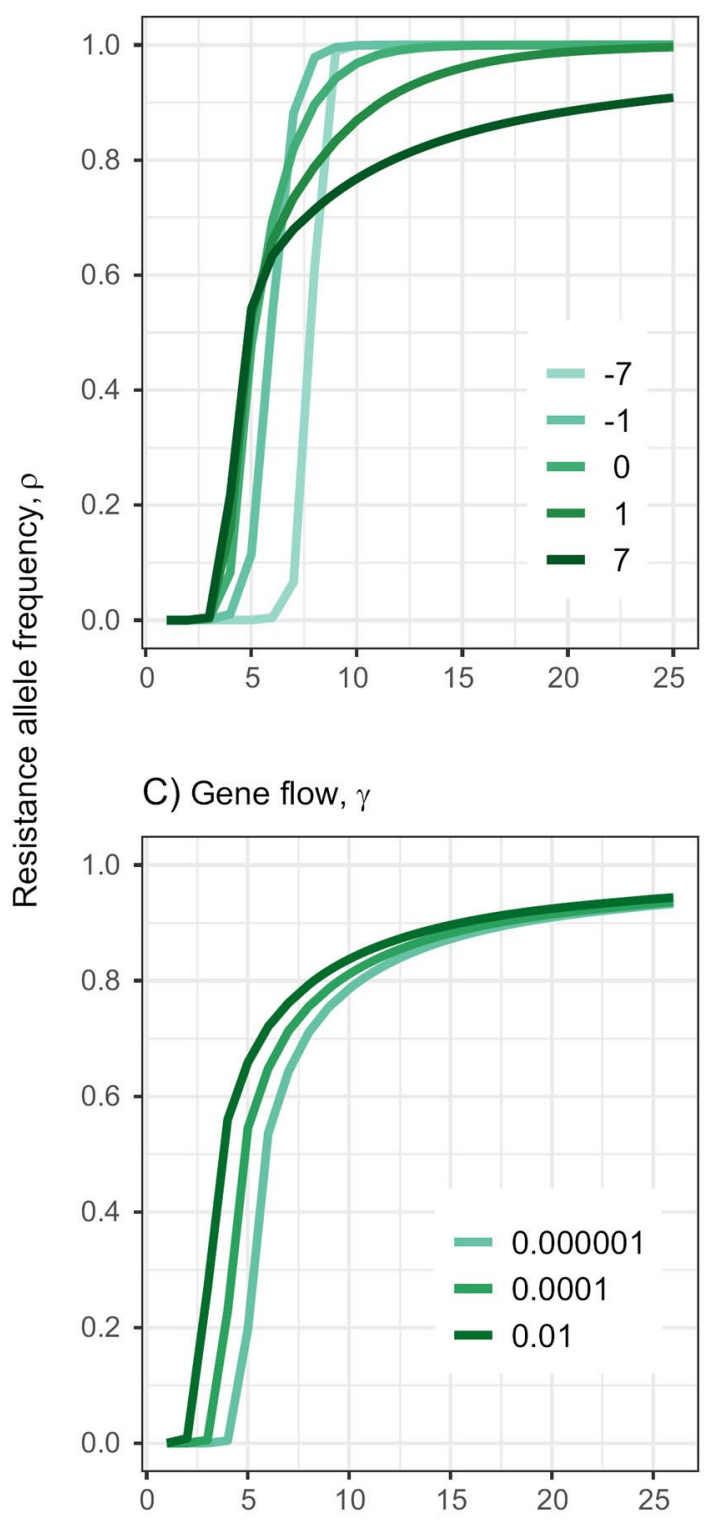

Tetraploid plants

B) Degree of dominance, $h$

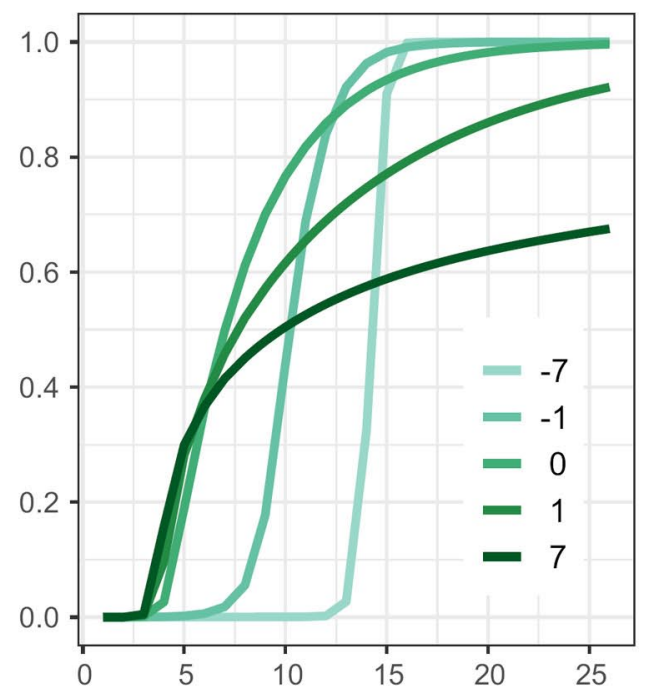

D) Gene flow, $\gamma$

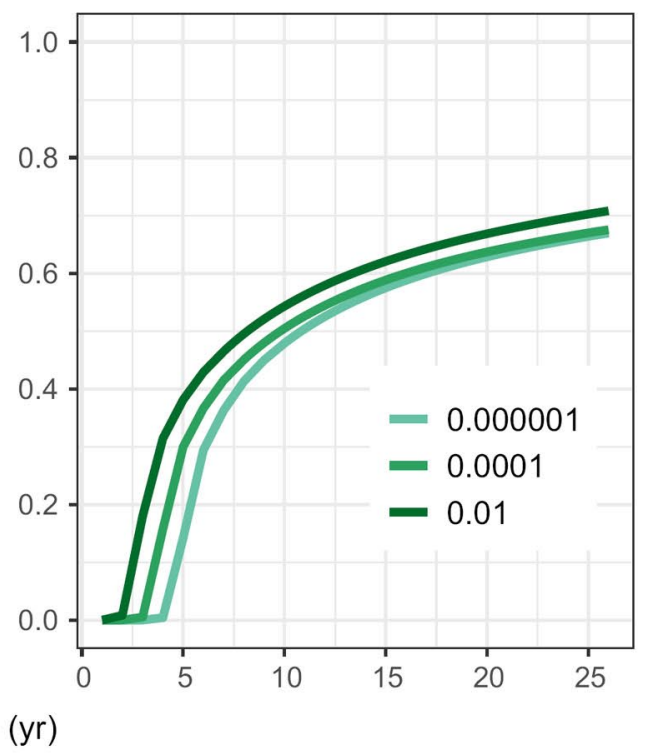

Fig. 7. (A, B) Effect of degree of dominance $h$ and (C, D) gene flow on the predicted evolution of herbicide resistance in (A, C) diploid and (B, D) tetraploid Johnsongrass plants assuming the worst case scenario where Inzen sorghum is planted every year. An $h=7$ implies genotypes $R R R R, r R R R, r r R R$, and $r r R$ have a $100 \%$ chance of surviving ALS herbicide application, while $h=-7$ implies only the genotype $R R R R$ survives ALS herbicide application (Appendix S2: Fig. S1, $R$ indicates a resistance allele and $r$ susceptible allele) The baseline values for $\gamma=0.0001$ (A and B) and $h=7$ (C and D); all other parameter values are listed in Appendix S1: Tables S1-S3. 
(Fig. 7A,B). If plants are tetraploid and resistance alleles are recessive $(h<0)$ then initially the frequency of the resistance alleles is virtually undetectable, but after about $7(h=-1)$ or 15 yr $(h=-7)$ the frequency increases rapidly and the resistance alleles are fixed at $p=1$ after only more 5 years. If plants are diploid and resistance alleles are recessive $(h$ $<0$ ), the duration of extremely low resistance allele frequency is shorter and fixation occurs after only $10 \mathrm{yr}$. Overall, the qualitative effect of dominance on resistance evolution is independent of the ploidy level. Gene flow, $\gamma$.-We varied the rate of gene flow, $\gamma$, by choosing values two orders of magnitude higher and lower than the baseline value $(\gamma=0.0001)$. Unsurprisingly, the higher the rate of gene flow, the faster the evolution of resistance (Fig. 7C, D), but the effect is very small and similar in magnitude for diploid and tetraploid plants.

\section{Discussion}

\section{Life history and crop rotation}

We can evaluate the effect of life history on the effectiveness of crop rotation to slow the speed of herbicide resistance evolution by comparing the predictions of our model on a rhizomatous perennial weed species with the model predictions of an annual weed species (shattercane; Werle et al. 2017b). The comparison is ideal because both models consider the same crop rotation strategies and consider gene flow between a grain sorghum crop and a closely related weed species. The qualitative predictions of both models are similar (Fig. 3): weed population size is highest when Inzen sorghum is planted continuously $\left(\omega_{1}\right.$ and $\left.\omega_{2}\right)$, followed by rotations including soybeans $\left(\omega_{3}\right.$ and $\left.\omega_{4}\right)$, and weed population size is lowest for rotations including wheat and no crop $\left(\omega_{5}\right.$ and $\left.\omega_{6}\right)$. The predicted population sizes follow from the total survival probability following herbicide applications. For instance, Johnsongrass culm survival in sorghum $=0.4$, in soybean $=0.01$, and in wheat and non-crop $=0.005$ (Appendix S1: Table S3). However, asymptotic culm densities are generally lower in Johnsongrass, driving weed densities virtually extinct in $\omega_{5}$ and $\omega_{6}$ whereas shattercane still persists at very low densities $(>10$ plants $/ \mathrm{m}^{2}$ ) in $\omega_{5}$ and $\omega_{6}$. In contrast, the densities of seeds in the seedbank are higher in persisting Johnsongrass populations $\left(\omega_{1}-\omega_{4}\right)$. This 
is expected because culms emerging from rhizomes are typically larger and produce more seeds compared to culms germinating from seeds. The predicted high seed density might be important for managing perennial weed species with a persistent seed bank such as Plantago major (Christoffoleti and Caetano 1998), Cirsium arvense (L.) Scop., Asclepias syriaca L., and Rumex crispus L. (Burnside et al. 1996).

The predicted effect of crop rotation on the evolution of resistance in the rhizomatous perennial Johnsongrass and the annual shattercane is also similar (Werle et al. 2017a) in that the speed of resistance evolution increases with the frequency of Inzen sorghum in the crop rotation (Fig. 4). Resistance evolution is fastest when imposing selection pressure every year (Fig. $\left.4, \omega_{1}\right)$, followed by every other year $\left(\omega_{2}\right.$ and $\left.\omega_{4}\right)$, followed by every $3 \mathrm{yr}\left(\omega_{5}\right)$, followed by every $4 \mathrm{yr}\left(\omega_{5}\right)$, and is slowest if Inzen is planted every $6 \mathrm{yr}\left(\omega_{6}\right)$. However, the increase in the predicted frequency of resistance alleles in the population is much slower in the perennial species compared to the annual species. For instance, when applying selection pressure every year $\left(\omega_{1}\right)$, the predicted allele frequency in Johnsongrass populations is $<70 \%$ after 20 yr compared to $>90 \%$ in the annual shattercane. We predict a similar difference between diploid and tetraploid Johnsongrass assuming $h=7$ (Fig. 1A, B; line with darkest green value), which is equivalent to the dominance assumptions in Werle et al. (2017a). This suggests that the difference between the predicted speed of resistance evolution in shattercane (Werle et al. 2017a) and Johnsongrass is mainly due to the difference in ploidy level.

In conclusion, as predicted for annual species (Neve et al. 2011a, Renton et al. 2011, Bagavathiannan et al. 2013, 2014, Liu et al. 2017, Somerville et al. 2017, Werle et al. 2017a, Evans et al. 2018, b) crop rotation in combination with herbicide rotation can effectively mitigate the expansion of perennial weed populations and slows the evolution of herbicide resistance.

\section{Variation in herbicide effectiveness}

We expected that variation in herbicide effectiveness would affect the predicted change in allele frequency over time because of nonlinear averaging (Jensen's inequality), and that the magnitude and direction of the difference would be frequency dependent (Fig. 1). As expected, our model suggests that the effect of between year variation in survival of 
herbicide application of culms $(\sigma)$ and buds $(\tau)$ on resistance evolution is context dependent. If the spread of herbicide resistance is very slow because the model starts out with zero resistance alleles in the weed population and the gene flow between the crop and weed is very small, then ignoring the effect of variation tends to over-predict the speed of resistance evolution (orange line in Fig. 5 increases faster than the green line). Overall, in this case the effect of ignoring the variation in herbicide effectiveness is small. This would be consistent with Fig. 1, where the change in allele frequency is close to linear. In contrast, our model predicts a significant underestimation of the speed of resistance evolution (green line in Fig. 6 increases faster than the orange line) if the weed population already contains a small proportion of resistance alleles (0.0006) when Inzen is planted for the first time, because the spread of the resistance alleles increases quickly due to both the opportunity for crop-to-weed gene flow and the lack of ploidy-based reproductive barriers among existing resistant Johnsongrass plants. In the latter scenario (Fig. 6), the distribution of possible allele frequencies is highly skewed (green line is the upper 95\% confidence interval) because in most years almost all susceptible plants die resulting in a drastic increase in the proportion of resistance allele frequencies. This would be consistent with the allele frequency reaching the convex up part of Fig. 1 quickly. This prediction is important because most weed populations are assumed to contain low frequency of resistance alleles prior to herbicide first use.

In conclusion, incorporating the effect of variation in selection pressure is important when predicting evolutionary trajectories, as has been suggested by Ruel and Ayres (1999). Our work suggests that weed managers may slow the speed of resistance evolution if they were to minimize variation in herbicide effectiveness. Consistency in mortality rate is also a key factor in predicting the evolution of insecticide resistance in stored grain pests (Shi and Collins 2013).

\section{Genetic assumptions}

For evaluating the effect of genetic assumptions on the speed of resistance evolution, we assume the continuous use of Inzen sorghum where selection pressure is imposed every year $\left(\omega_{1}\right)$. We compared the effect of degree of dominance $(h)$ and gene flow $(\gamma)$ for diploid (Fig. 7A, C) and 
tetraploid plants (Fig. 7B, D) on resistance evolution. For the sake of parsimony, we assume the initial frequency of resistance alleles in the Johnsongrass population is zero.

First, our model predicted that the frequency of herbicide-resistance alleles increased much faster in diploid plants compared to tetraploid plants, and the effect is independent of the degree of dominance or geneflow level. Resistance evolution is influenced by the ploidy level because herbicide selection is performed on the whole plant phenotype, not on individual alleles. In our model, herbicide resistance is a dominant trait, which means that surviving herbicide application requires only a single resistance allele. In diploid plants, heterozygote genotypes $(R r)$ mask one susceptible allele and pass it on to the next generation while, in tetraploid plants, heterozygote genotypes ( $R r r r, R R r r, R R R r$ ) may be able to mask one to three susceptible alleles, which slows the elimination of susceptible alleles. We could only find two empirical examples exploring the effect of ploidy level on the evolution of beneficial gene variants (reviewed in Kreiner and Stinchcombe 2018). In yeast, polyploidy sped up beneficial adaptation rates, but only if population size and mutation rates were small (Zeyl and Vanderford 2003, Anderson and Sirjusingh 2004, Selmecki 2015). In contrast, there is anecdotal evidence that polyploidy in the hexaploid oat, Avena fatua, is limiting resistance evolution to the herbicide acetyl-CoA carboxylase (ACCase; Yu et al. 2013).

Second, our model predicted that initially the speed of herbicide resistance evolution increased with the degree of dominance (larger $h$ values) but, after a few years, the effect of dominance was reversed and resistance evolution decreased with increased degree of dominance (Fig. $7 A, B)$. Our model points to the possibility of a future sudden jump in the number of plant species that are resistant to herbicides because current recessive mutations could be hidden for a long time. Until now, the majority of herbicide resistance target site mutations reported in the literature are partially or completely dominant (Shaaltiel et al. 1988, Sebastian et al. 1989, Miki et al. 1990, Parker et al. 1990, Newhouse et al. 1991, Lorraine-Colwill et al. 2001, Tranel et al. 2002, Roux and Gasquez 2004, Roux et al. 2005, Paris et al. 2008, Scarabel et al. 2011), but recessive mutations have also been identified (Roux et al. 2005).

Third, our model predicted that the greater the crop-to-weed geneflow frequency, the faster the evolution of herbicide resistance, but the overall effect is small and is strongest during the early years of selection. 
These predictions are consistent with Werle et al. (2017a) who considered a species reproducing exclusively via seeds. The rate of gene transfer between tetraploid Johnsongrass and diploid sorghum is likely very small $(\gamma=0.0001)$ due to ploidy differences between the two species, but preliminary field experiments by Subramanian et al. (2020) reported outcrossing rates between Johnsongrass and Inzen sorghum as high as 0.5-1\%. However, even when using a $\gamma$ value of 0.01 effect on the predicted evolutionary trajectory is likely small (Fig. 7 D). This does not mean that gene transfer can be neglected in weed management. First, for some weed species the gene flow might be even higher than considered here. For instance, in situ hybridization of neighboring sorghum and shattercane ( $S$. bicolor ssp. drummondii) plants can be as high as 0.25 (Schmidt et al. 2013). Second, for some systems the rate of gene flow by far exceeds the frequency of spontaneous mutation or the natural frequency of the herbicide resistance alleles in the population. For instance, the mutation rate for the target gene conferring resistance to the herbicide glyphosate is assumed to be $5 \times 10^{9}$ (Neve et al. 2011a). In cases where gene flow from a crop to a weedy relative is possible, gene flow will likely play a more important role for herbicide-resistance evolution than mutation. In addition, in weed populations already segregating for herbicide-resistance alleles, no ploidy reproductive barrier to withinpopulation gene flow exists, and further hastens the spread of the trait under selective pressures imposed by herbicides.

In conclusion, our comparison of the effect of genetic assumptions on model predictions reveals that the degree of dominance and presence of ploidy differences between the crop and weed in question have the greatest effect on the predicted speed of resistance evolution.

\section{Random mating assumption}

Our model assumed that seeds are derived from randomly mating gametes; however, Johnsongrass is able to self-pollinate, so it is likely that a proportion of plants in the field are derived from self-pollination. Since, under selfing, two gametes are inherited from the same parent, the proportion of homozygotes in the population increases, and a stronger selective pressure is exerted on alleles that may influence adaptation. This would increase the speed at which resistance-allele frequency increases in the proportion of plants derived from self-pollination vs. 
plants derived from cross-pollination. Accordingly, theoretical work by Glémin and Ronfort (2013) predicted faster adaptation in self than in outcrossing plants or species. Hence, our model likely underestimated the speed of resistance evolution in the population as a whole.

\section{Management implications}

There are several factors impacting the rates of evolutionary processes that require special attention by farm managers. These include an awareness of choices about which crops they grow, whether to plant herbicideresistant crops that have wild relatives, which herbicides they use, and which crop rotations they implement. Our model suggests that perennial weeds are unlikely to pose a higher risk for resistance evolution compared to annual weeds. As with annual weeds, herbicide resistance evolution is fastest when imposing selection pressure every year (e.g., via ALS-inhibiting herbicides). Additionally, perennial rhizomatous weeds might produce a larger seed bank compared to annual weeds because seeds are not only produced by seedlings but also by sprouts, which produce more seeds compared to seedlings. Our results suggest that it is important to choose management strategies that not only reduce the average but also the variation in the percentage of weeds surviving herbicide application. These choices are likely to impact the specific weed species and weed population density on their land.

Acknowledgments This project was funded by a USDA-NIFA Grant 2017- 03807. B. Tenhumberg was financially supported by the U.S. National Science Foundation (DEB 1655117). We thank two anonymous reviewers for their helpful comments.

\section{Literature cited}

Anderson, J. B., C. Sirjusingh, and N. Ricker. 2004. Haploidy, diploidy and evolution of antifungal drug resistance in Saccharomyces cerevisiae. Genetics 168:1915-1923.

Bagavathiannan, M. V., J. L. Norsworthy, K. L. Smith, and P. Neve. 2013. Modeling the evolution of glyphosate resistance in barnyardgrass (Echinochloa crus-galli) in cotton-based production systems of the midsouthern United States. Weed Technology 27:475-487.

Bagavathiannan, M. V., J. L. Norsworthy, K. L. Smith, and P. Neve. 2014. Modeling the simultaneous evolution of resistance to ALS- and ACCase-inhibiting herbicides 
in barnyardgrass (Echinochloa crus-galli) in Clearfield rice. Weed Technology 28:89-103.

Barton, N. H., and M. Turelli. 1989. Evolutionary quantitative genetics: how little do we know? Annual Review of Genetics 23:337-370.

Bowman, H. D., T. Barber, J. K. Norsworthy, T. L. Roberts, J. Kelley, and E. E. Gbur. 2021. Resistance of Inzen_grain sorghum to multiple PRE-and POST-applied acetolactate synthase-inhibiting herbicides. Weed Technology 35:57-64.

Brookes, G., and P. Barfoot. 2017. Environmental impacts of genetically modified (GM) crop use 1996-2015: Impacts on pesticide use and carbon emissions. GM Crops \& Food 8:117-147.

Caswell, H. 2001. Matrix population models. Second edition. Sinauer Associates, Sunderland, Massachusetts, USA.

Christoffoleti, P. J., and R. S. X. Caetano. 1998. Soil seed banks. Scientia Agricola 55(SPE):74-78.

DeFelice, M. S. 2006. Shattercane, Sorghum bicolor (L.) Moench ssp. drummondii (Nees ex steud.) de wet ex davidse-black sheep of the family. Weed Technology 20:1076-1083.

Délye, C., C. Deulvot, and B. Chauvel. 2013. DNA analysis of herbarium specimens of the grass weed Alopecurus myosuroides reveals herbicide resistance pre-dated herbicides. PLoS One 8:e75117.

Duke, S. 0. 2012. Why have no new herbicide modes of action appeared in recent years? Pest Management Science 68:505-512.

Ellner, S., and N. G. Hairston, Jr. 1994. Role of overlapping generations in maintaining genetic variation in a fluctuating environment. American Naturalist 143:403-417.

Ellstrand, N. C. 2001. When transgenes wander, should we worry? Plant Physiology 125:1543-1545.

Ellstrand, N. C. 2014. Is gene flow the most important evolutionary force in plants? American Journal of Botany 101:737-753.

Ellstrand, N. C., H. C. Prentice, and J. F. Hancock. 1999. Gene flow and introgression from domesticated plants into their wild relatives. Annual Review of Ecology, Evolution and Systematics 30:539-563.

Evans, J. A., A. Williams, A. G. Hager, S. B. Mirsky, P. J. Tranel, and A. S. Davis. 2018. Confronting herbicide resistance with cooperative management. Pest Management Science. https://doi.org/10.1002/ps.5105

Firbank, L. G., and A. R. Watkinson. 1985. On the analysis of competition within twospecies mixtures of plants. Journal of Applied Ecology 22:503-517.

Fisher, R. A. 1930. The genetical theory of natural selection. Oxford University Press, Oxford, UK.

Gianessi, L. P., and N. P. Reigner. 2007. The value of herbicides in US crop production. Weed Technology 21:559-566.

Glémin, S., and J. Ronfort. 2013. Adaptation and maladaptation in selfing and outcrossing species: new mutations versus standing variation. Evolution 67:225-240. 
Godar, A. S., V. K. Varanasi, S. Nakka, P. V. Prasad, C. R. Thompson, and J. Mithila. 2015. Physiological and molecular mechanisms of differential sensitivity of Palmer amaranth (Amaranthus palmeri) to mesotrione at varying growth temperatures. PLoS One 10:e0126731.

Gould, F., Z. S. Brown, and J. Kuzma. 2018. Wicked evolution: Can we address the sociobiological dilemma of pesticide resistance? Science 360:728-732.

Hairston, N. G. ,.Jr., and B. T. De Stasio, Jr. 1988. Rate of evolution slowed by a dormant propagule pool. Nature (London) 336:239-242.

Hartzler, B. 2020. Take Action Herbicide Resistance Management group-Weed Out Resistance. https://iwilltakeaction.com/uploads/files/20200921-factsheet11threaten-posterusdadraft.pdf

Heap, I. 2019. The International Survey of Herbicide Resistant Weeds. www. weedscience.org

Heino, M., J. A. J. Metz, and V. Kaitala. 1998. The enigma of frequency-dependent selection. Trends in Ecology and Evolution 13:367-370.

Hicks, H. L., D. Comont, S. R. Coutts, L. Crook, R. Hull, K. Norris, P. Neve, D. Z. Childs, and R. P. Freckleton. 2018. The factors driving evolved herbicide resistance at a national scale. Nature Ecology \& Evolution 2:529-536.

Holm, L. G., D. L. Plocknett, J. V. Pancho, and J. P. Herberger. 1977. The world's worst weeds: distribution and biology. University Press of Hawaii, Honolulu, Hawaii, USA.

Jensen, J. L. 1906. Sur les fonctions convexes et les inégualités entre les valeurs moyennes. Acta Mathematica 30:175-193.

Kiang, Y. T., J. Antonovics, and L. Wu. 1979. The extinction of wild rice (Oryza perennis formosana) in Taiwan. Journal of Asian Ecology 1:1-9.

Kreiner, J. M., J. R. Stinchcombe, and S. I. Wright. 2018. Population genomics of herbicide resistance: adaptation via evolutionary rescue. Annual Review of Plant Biology 69:611-635.

Lande, R. 1977. The influence of the mating system on the maintenance of genetic variability in polygenic characters. Genetics 86:485-498.

Lande, R. 2007. Expected relative fitness and the adaptive topography of fluctuating selection. Evolution 61:1835-1846.

Lande, R., E. Steinar, and Sæther, B.-E. 2009. An evolutionary maximum principle for density-dependent population dynamics in a fluctuating environment. Philosophical Transactions of the Royal Society B 364:1511-1518.

Liu, C., M. E. Bridges, S. S. Kaundun, L. Glasgow, M. D. Owen, and P. Neve. 2017. A generalised individual-based algorithm for modelling the evolution of quantitative herbicide resistance in arable weed populations. Pest Management Science 73:462-474.

Liu, C., J. A. Scursoni, R. Moreno, I. A. Zelaya, M. S. Muñoz, and S. S. Kaundun. 2019. An individual-based model of seed- and rhizome-propagated perennial plant species and sustainable management of (Sorghum halepense) in soybean production systems in Argentina. Ecology and Evolution 9 (17):10017-10028. 
Lorraine-Colwill, D. F., S. B. Powles, T. R. Hawkes, and C. Preston. 2001. Inheritance of evolved glyphosate resistance in Lolium rigidum (Gaud.). Theoretical and Applied Genetics 102:545-550.

Mace, E. S., et al. 2013. Whole-genome sequencing reveals untapped genetic potential in Africa's indigenous cereal crop sorghum. Nature Communications 4:1-9.

McWhorter, C. G. 1971. Introduction and spread of Johnsongrass in the United States. Weed Science 19:496-500.

McWhorter, C. G. 1989. History, biology, and control of Johnsongrass. Review of Weed Science 4:85-121.

Melander, B. 1994. Modelling the effects of Elymus repens (L.) Gould competition on yield of cereals, peas and oilseed rape. Weed Research 34:99-108.

Miki, B. L., H. Labbé, J. Hattori, T. Ouellet, J. Gabard, G. Sunohara, P. J. Charest, and V. N. Iyer. 1990. Transformation of Brassica napus canola cultivars with Arabidopsis thaliana acetohydroxyacid synthase genes and analysis of herbicide resistance. Theoretical and Applied Genetics 80:449-458.

Mitskas, M. B., C. E. Tsolis, I. G. Eleftherohorinos, and C. A. Damalas. 2003. Interference between corn and johnsongrass (Sorghum halepense) from seed or rhizomes. Weed Science 51:540-545.

Morrell, P. L., T. D. Williams-Coplin, A. L. Lattu, J. E. Bowers, J. M. Chandler, and A. H. Paterson. 2005. Crop-to-weed introgression has impacted allelic composition of johnsongrass populations with and without recent exposure to cultivated sorghum. Molecular Ecology 14:2143-2154.

Neve, P. 2008. Simulation modelling to understand the evolution and management of glyphosate resistance in weeds. Pest Management Science 64:392-401.

Neve, P., J. K. Norsworthy, K. L. Smith, and I. A. Zelaya. 2011a. Modelling evolution and management of glyphosate resistance in Amaranthus palmeri. Weed Research 51:99- 112.

Neve, P., J. K. Norsworthy, K. L. Smith, and I. A. Zelaya. 2011b. Modeling glyphosate resistance management strategies for Palmer amaranth (Amaranthus palmeri) in cotton. Weed Technology 25:335-343.

Newhouse, K., B. Singh, D. Shaner, and M. Stidham. 1991. Mutations in corn (Zea mays L.) conferring resistance to imidazolinone herbicides. Theoretical and Applied Genetics 83:65-70.

Norsworthy, J., et al. 2012. Reducing the risks of herbicide resistance: best management practices and recommendations. Weed Science 60(SP1):31-62. Special Issue.

Ohadi, S., G. Hodnett, W. Rooney, and M. Bagavathiannan. 2017. Gene flow and its consequences in Sorghum spp. Critical Reviews in Plant Sciences 36:367-385.

Otto, S. P., and J. Whitton. 2000. Polyploid incidence and evolution. Annual Review of Genetics 34:401-437.

Paris, M., F. Roux, A. Berard, and X. Reboud. 2008. The effects of the genetic background on herbicide resistance fitness cost and its associated dominance in Arabidopsis thaliana. Heredity 101:499-506. 
Parker, W. B., L. C. Marshall, J. D. Burton, D. A. Somers, D. L. Wyse, J. W. Gronwald, and B. G. Gengenbach. 1990. Dominant mutations causing alterations in acetylcoenzyme A carboxylase confer tolerance to cyclohexanedione and aryloxyphenoxypropionate herbicides in maize. Proceedings of the National Academy of Sciences USA 87:7175-7179.

Preston, C., and C. A. Mallory-Smith 2001. Biochemical mechanisms, inheritance, and molecular genetics of herbicide resistance in weeds. Pages 23-60 in S. B. Powles and D. L. Shaner, editors. Herbicide resistance and world grains. CRC Press, Boca Raton Florida, USA.

R Core Team. 2018. R version 3.5.1. R Project for Statistical Computing, Vienna, Austria. https://www.R-project.org

Renton, M., R. Busi, P. Neve, D. Thornby, and M. Vila-Aiub. 2014. Herbicide resistance modelling: past, present and future. Pest Management Science 70:1394-1404.

Renton, M., A. Diggle, S. Manalil, and S. Powles. 2011. Does cutting herbicide rates threaten the sustainability of weed management in cropping systems? Journal of Theoretical Biology 283:14-27.

Ridley, C. E., and L. C. Alexander. 2016. Applying gene flow science to environmental policy needs: a boundary work perspective. Evolutionary Applications 9:924-936.

Roughgarden, J. 1998. Primer of ecological theory. Prentice Hall, Upper Saddle River, New Jersey, USA.

Roux, F., J. Gasquez, and X. Reboud. 2004. The dominance of the herbicide resistance cost in several Arabidopsis thaliana mutant lines. Genetics 166:449-460.

Roux, F., A. Matéjicek, J. Gasquez, and X. Reboud. 2005. Dominance variation across six herbicides of the Arabidopsis thaliana csr1-1 and csr1-2 resistance alleles. Pest Management Science 61:1089-1095.

Ruel, J. J., and M. P. Ayres. 1999. Jensen's inequality predicts effects of environmental variation. Trends in Ecology \& Evolution 14:361-366.

Sæther, B.-E., and E. Steiner. 2015. The concept of fitness in fluctuating environments. Trends in Ecology \& Evolution 30:273-281.

Scarabel, L., S. Panozzo, S. Varotto, and M. Sattin. 2011. Allelic variation of the ACCase gene and response to ACCase-inhibiting herbicides in pinoxaden-resistant Lolium spp. Pest Management Science 67:932-941.

Schafer, M. G., A. A. Ross, J. P. Londo, C. A. Burdick, E. H. Lee, S. E. Travers, P. K. Van de Water, and C. L. Sagers. 2011. The establishment of genetically engineered canola populations in the US. PLoS One 6:e25736.

Schlegel, A. J., Y. Assefa, D. O’Brien, F. R. Lamm, L. A. Haag, and L. R. Stone. 2016. Comparison of Corn, Grain Sorghum, Soybean, and Sunflower under Limited Irrigation. Agronomy Journal 108:670-679.

Schmidt, J. J., J. F. Pedersen, M. L. Bernards, and J. L. Lindquist. 2013. Rate of shattercane $\times$ sorghum hybridization in situ. Crop Science 53:1677-1685.

Schmitz, J., K. Schäfer, and C. A. Brühl. 2014. Agrochemicals in field marginsfield evaluation of plant reproduction effects. Agriculture, Ecosystems and Environment 189:82-91. 
Schütte, G., M. Eckerstorfer, V. Rastelli, W. Reichenbecher, S. Restrepo-Vassalli, M. Ruohonen-Lehto, A.-G. Wuest Saucy, and M. Mertens. 2017. Herbicide resistance and biodiversity: agronomic and environmental aspects of genetically modified herbicide-resistant plants. Environmental Sciences Europe 29:1-12.

Sebastian, S. A., G. M. Fader, J. F. Ulrich, D. R. Forney, and R. S. Chaleff. 1989. Semidominant soybean mutation for resistance to sulfonylurea herbicides. Crop Science 29:1403- 1408.

Selmecki, A. M., et al. 2015. Polyploidy can drive rapid adaptation in yeast. Nature 519:349-352.

Shaaltiel, Y., N. H. Chua, S. Gepstein, and J. Gressel. 1988. Dominant pleiotropy controls enzymes cosegregating with paraquat resistance in Conyza bonariensis. Theoretical and Applied Genetics 75:850-856.

Shi, M., P. J. Collins, T. J. Ridsdill-Smith, R. N. Emery, and M. Renton. 2013. Dosage consistency is the key factor in avoiding evolution of resistance to phosphine and population increase in stored-grain pests. Pest Management Science 69:1049-1060.

Small, E. 1984. Hybridization in the domesticated-weed-wild complex. Plant Biosystematics 195:210.

Somerville, G. J., S. B. Powles, M. J. Walsh, and M. Renton. 2017. How do spatial heterogeneity and dispersal in weed population models affect predictions of herbicide resistance evolution? Ecological Modelling 362:37-53.

Stebbins, G. L. 1971. Processes of organic evolution. Englewood Cliffs, Prentice-Hall, New Jersey, USA.

Subramanian, N., D. Lavy, C. Sias, G. Hodnett, W. Rooney, and M. Bagavathiannan 2020. Understanding gene flow from grain sorghum (Sorghum bicolor) to johnsongrass (S. halepense). In Proceedings of the Weed Science Society of America Annual Meeting, Maui, HI. https://wssa.net/wp-content/uploads/WSSAWSWS-2020-Proceedings.html

Templeton, A. R., and D. A. Levin 1979. D. A. Evolutionary consequences of seed pools. American Naturalist 114:232-249.

Tenhumberg, B., T. Suwa, A. J. Tyre, F. L. Russell, and S. M. Louda. 2015. Integral projection models show exotic thistle is more limited than native thistle by ambient competition and herbivory. Ecosphere 6:1-18.

Tranel, J., J. Wassom, R. Jeschke, and L. Rayburn. 2002. Transmission of herbicide resistance from a monoecious to a dioecious weedy Amaranthus species. Theoretical and Applied Genetics 105:674-679.

Turelli, M. 1988. Population genetic models for polygenic variation and evolution.

Pages 601-618 in E. J. Eisen, M. M. Goodman, G. Namkoong, and B. S. Weir, editors. The Second International Conference on Quantitative Genetics. Sinauer, Boston, Massachusetts, USA.

Venable, D. L. 1989. Modeling the evolutionary ecology of seed banks. Pages 67-90 in M. A. Leck, V. T. Parker, and R. L. Simpson, editors. Ecology of soil seed banks. Academic Press, New York, New York, USA. 
Warwick, S. I., and L. D. Black. 1983. The biology of Canadian weeds.: 61. Sorghum halepense (L.) PERS. Canadian Journal of Plant Science 63:997-1014.

Weed Science Society of America. 2017. 2017 Survey for weeds in grass crops, pasture and turf. Weed Science Society of America. http://wssa.net/wssa/weed/ surveys/

Werle, R., K. Begcy, M. K. Yerka, J. P. Mower, I. Dweikat, A. J. Jhala, and J. Lindquist. 2017a. Independent evolution of acetolactate synthase-inhibiting herbicide resistance in weedy Sorghum populations across common geographic regions. Weed Science 65:164-176.

Werle, R., B. Tenhumberg, and J. L. Lindquist. 2017b. Modeling shattercane dynamics in herbicide-tolerant grain sorghum cropping systems. Ecological Modelling 343:131-141.

Wood, T. E., N. Takebayashi, M. S. Barker, I. Mayrose, P. B. Greenspoon, and L. H. Rieseberg. 2009. The frequency of polyploid speciation in vascular plants. Proceedings of the National Academy of Sciences USA 106:13875-21379.

Wright, S. 1969. Evolution and the genetics of populations. University of Chicago Press, Chicago, Illinois, USA.

Yu, Q., M. S. Ahmad-Hamdani, H. Han, M. J. Christoffers, and S. B. Powles. 2013. Herbicide resistance-endowing ACCase gene mutations in hexaploid wild oat (Avena fatua): insights into resistance evolution in a hexaploid species. Heredity 110:220-231.

Zeyl, C., T. Vanderford, and M. Carter. 2003. An evolutionary advantage of haploidy in large yeast populations. Science 299:555-558.

Supporting Information follows. 
Supporting Information. Holmes, K. H., Lindquist, J.L., Rebarber, R., Werle, R., Yerka, M., and Tenhumberg, B. Modeling the evolution of herbicide resistance in weed species with a complex life cycle. Ecological Applications.

Appendix S1 


\section{Johnsongrass Model Parameters}

Seed Survival (Table S1): Seed survival is generally measured from one growing season to the next. According to Bagavathiannan and Norsworthy (2013) the survival of Johnsongrass seeds from time of dispersal in the autumn through the next autumn was less than $8 \%$, and $75 \%$ of the seed mortality during that period is due to postdispersal seed predation. It is fair to assume that seed survival during the winter is lower compared to the rest of the year, so, we assume that monthly survival during April-October is 0.92 and during the rest of the year it is 0.82 . Since survival is multiplicative, this implies $s_{1 N}$ $=0.82^{5}=0.37, s_{1 A}=0.92^{2}=0.85, s_{1 J}=0.92^{5}=0.66$. Then the annual seed survival is $s_{1 N} * s_{1 A} * s_{1 J} * s_{1 P}=0.37 * 0.85 * 0.66 * 0.35=0.073$. These values are within the range of Bagavathiannan and Norsworthy (2013) but lower than those reported in other studies (Egley and Chandler 1978; Leguizamon 1986).

Bud Survival (Table S1): We use Johnsongrass rhizome survival reported in the literature as a surrogate for bud survival. Rhizome survival depends on rhizome age and generally increases with soil depth (Warwick et al. 1986). To keep the model tractable, we do not account for varying bud survival at different soil depths. Soil temperature is also a major factor influencing bud survival that could not be accounted for in the model. To measure rhizome survival in the field, rhizomes are typically buried in soil in the fall, exhumed in spring, and assessed for viability by following sprout emergence in a greenhouse. Survival of these one-year old rhizomes varies between $0-60 \%$ (Stoller 1977, Hartzler 1991). We assume that these studies provide an adequate estimate for annual survival. When a bud on a rhizome sprouts, the entire rhizome disintegrates 
within about 3 weeks (Monaghan (1979), citing McWhorter (1961) and Anderson et al. (1960)). Unsprouted rhizomes are unlikely to survive a second growing season and winter. Hence our model distinguishes between overwinter survival of newly produced buds and older buds (> one year old), with the latter having a very much lower overwinter survival $\left(s_{2 N 1}>s_{2 N 2}\right)$. It is fair to assume that survival during the winter is lower than during the rest of the year. Hence, we assume that monthly bud survival during April-October is 0.93 , and 0.84 during the rest of the year for one-year old buds, and 0.63 for older buds. This implies $s_{2 N 1}=0.84^{5}=0.42, s_{2 N 2}=0.63^{5}=0.1, s_{2 A}=0.93^{2}=0.86$, $s_{2 J}=0.93^{5}=0.7$. Therefore, the annual bud survival is $s_{2 N 1} * s_{2 A} * s_{2 J}=0.42 * 0.86 * 0.7$ $=0.25$, which is consistent with rhizome survival reported in the literature.

Seedling and sprout survival (self-thinning) (Table S1): We found no information in the literature on self-thinning in Johnsongrass. Our investigation of density dependent seed production in naturally occurring Johnsongrass stands (Don Treptow MS thesis, in prep) indicated that Johnsongrass density rarely exceeded about 125 culms $m^{-2}$, so a value of $1 / 125=0.008$ was chosen for both $\alpha_{3 A}$ and $\alpha_{4 A}$. Since sprouts are expected to be considerably larger and more competitive than seedlings, we selected a value of 2.0 and 0.5 for $\delta_{3 A}$ and $\delta_{4 A}$, respectively.

Seed germination and bud sprouting (Table S1): Temperature is the most important driver of Johnsongrass seed germination and bud sprout (Holshouser et al. 1996, Rosales-Robles et al. 2003). However, temperature cannot be accounted for in our model. Horowitz (1972) reported germination from seeds and rhizomes at different temperatures, showing that maximum germination from seed was 53\% at temperatures between 
28 and $35^{\circ} \mathrm{C}$, but declining substantially below $28^{\circ} \mathrm{C}$. Warwick and Black (1983) reported Johnsongrass germination ranging from 38 to $76 \%$, whereas Taylorson and McWhorter (1969) reported that average germination of 44 ecotypes of Johnsongrass was only in the range of 34 to $39 \%$ at constant temperatures. Based on our field observations and the literature, we use a seed germination value, $\tilde{g}_{1}$ of 0.35 . Rhizome bud sprouting may be partially controlled by apical dominance (Monaghan 1979), but this is unclear and would be very difficult to implement in our model. Hull (1970) reported a wide range of values for the sprouting of buds harvested at different times of year. Our bud sprouting value $\left(\tilde{g}_{2}\right)$ of 0.73 is within the range of those reported.

Probability of gene transfer (Table S1): As far as we know the rate of gene transfer from diploid sorghum plants to tetraploid Johnsongrass is not well understood. A recent preliminary field study where Inzen sorghum was planted in naturally occuring Johnsograss patches reported outcrossing values between Johnsongrass and Inzen sorghum as $0.5-1 \%$ (Subramanian et al. 2020). Most of the offspring in the study were tetraploid and resistant to nicosulfuron herbicide. Since the study thus far only considered a single sorghum genotype, we use a conservative gene flow value in our model and set $\gamma=$ 0.0001. We also explored the effect of gene transfer on model predictions for $\gamma$-values ranging from 0.01 to 0.000001 .

Dominance of resistant genes (Table S1) Resistance to ALS-inhibiting herbicides is typically conferred by a single, nuclear-encoded gene that is either dominant or partially dominant (Preston and Mallory-Smith, 2001). In conventional sorghum and the closely related shattercane the ALS resistance trait is completely dominant (reviewed in Werle 
et al. 2017), but far as we know the degree of dominance for this trait is unknown for Johnsongrass. In our model the degree of dominance is controlled by the parameter $h$. We assume $h=7$, implying that only Johnsongrass genotypes with zero resistance genes (rrrr) are killed by ALS-inhibitor applications while all other genotypes (RRRR, rRRR, rrRR, and rrrR) survive. However, we explore the effect of lower degrees of dominance, including the effect of completely recessive inheritance $(h=-7)$, on model predictions.

Density dependent seed reproduction (Table S2): We found no information in the literature on density dependent Johnsongrass seed production. Field surveys similar to those of Werle et al. (2017) were conducted to obtain parameter estimates reported in Table S2 (Lindquist, unpublished data). Crop densities used for the model are common for crops produced in the northern Great Plains. The density estimate used for the noncrop area is based on data collected at roadsides in Nebraska populated with smooth brome at densities of $\geq 100 \mathrm{culms} / \mathrm{m}^{2}$.

Survival of herbicide applications (Table S3): In the crop rotations considered in this study, farmers commonly use the herbicides glyphosate, clethodim, and nicosulfuron (ALS-inhibitor). Depending on the crop planted, farmers spray these herbicides either before the crop emerges (PRE) and/or after crop emergence (POST). We estimated the survival of these herbicide applications (Table S3) from the literature, extension publications, expert opinion and also extrapolated information from the annual diploid Sorghum species shattercane (Table S3; Johnson et al. 2003; Knezevic et al. 2019; Obrigawitch et al. 1990; Roeth et al. 1994; Thompson et al. 2016). The effectiveness of the herbicide 
application largely varies from year to year and is dependent on early-season weather conditions, time of Johnsongrass culm emergence, and crop planting date. According to expert opinion, 40 to $80 \%$ of total Johnsongrass culms emerge prior to planting sorghum (conventional and Inzen) and will be killed by PRE herbicide applications. For our model we assume that $40 \%$ of Johnsongrass culms emerge after PRE herbicide applications and hence survive in conventional (non-Inzen) sorghum years. In non-crop years, PRE herbicides are applied later in the year (June-July) when all Johnsongrass culms have emerged, and consequently survival is only $0.5 \%$. POST emergence herbicides are also applied after all Johnsongrass culms are above ground, and very few survive the application (0.5-1\% survival) unless the herbicide is nicosulfuron (ALS-inhibitor) and plants are resistant. The herbicides considered in this study also affect the survival of buds because they are absorbed by foliage and translocated to the rhizomes (systemic herbicides). It is fair to assume that the dosage reaching the buds is lower compared to the aboveground plants tissue, which will likely result in greater survival of buds compared to culms.

\section{Literature Cited}

Anderson, L. E., A. P. Appleby \& J. W. Weselow. 1960. Characteristics of johnsongrass rhizomes. Weeds 8:402-406.

Bagavathiannan, M.V. \& Norsworthy, J.K., 2013. Postdispersal loss of important arable weed seeds in the midsouthern United States. Weed Science 61, 570—579. 
Burnside, O. C., Wilson, R. G., Weisberg, S., \& Hubbard, K. G. (1996). Seed longevity of 41 weed species buried 17 years in eastern and western Nebraska. Weed Science, 44(1), 74-86.

Egley, G. H. \& J. M. Chandler. 1978. Germination and viability of weed seeds after 2.5 years in a 50-year buried seed study. Weed Science 26:230-239.

Firbank, L. G. \& A. R. Watkinson. 1986. Modelling the population dynamics of an arable weed and its effects upon crop yield. Journal of Applied Ecology 23:147-159.

Hartzler, R. G., A. Gover \& J. Stellingwerf. 1991. Factors affecting winter survival of johnsongrass (Sorghum halepense) rhizomes. Weed Technology 5:108-110.

Holshouser, D. L., J. M. Chandler \& H. I. Wu. 1986. Temperature-dependent model for non-dormant seed germination and rhizome bud break of johnsongrass (Sorghum halepense). Weed Science 44:257-265.

Horowitz, M. 1972. Early development of Johnsongrass. Weed Science 20:271-273.

Hull, R. J. 1970. Germination control of johnsongrass rhizome buds. Weed Science 18:118121.

Johnson W.G., J. Li, \& J.D. Wait. 2003. Johnsongrass control, regrowth, and total non-structural carbohydrates in rhizomes following postemergence herbicides used in herbicide-resistant corn. Weed Technology 17:36-41.

Knezevic, S.Z., Creech, C.F., Jhala, A.J., Klein, R.N., Kruger, G.R., Proctor, C.A., Shea, P.J., Ogg, C.L., \& Lawrence, N., 2019. Guide for weed, disease, and insect management 
in Nebraska. University of Nebraska-Lincoln Extension. EC130.

Leguizamon, E. S. 1986. Seed survival and patterns of seedling emergence in Sorghum halepense (L.) Pers. Weed Research 26:397-403.

McWhorter, C. G. 1961. Morphology and development of johnsongrass plants from seeds and rhizomes. Weeds 9:558-562.

Mitskas, M. B., C. E. Tsolis, I. G. Eleftherohorinos \& C. A. Damalas. 2003. Interference between corn and johnsongrass (Sorghum halepense) from seed and rhizomes. Weed Science 51:5405-45.

Monaghan, N. 1979. The biology of Johnson grass (Sorghum halepense). Weed Research 19:261-267.

Obrigawitch, T.T., W.H. Kenyon, \& H. Kuratle. 1990. Effect of application timing on rhizome johnsongrass (Sorghum halapense) control with DPX-V9360. Weed Science 38:4549.

Peterson, D.E., Fick, W.H., Currie, R.S., Kumar, V., \& Slocombe, J.W., 2019. Chemical weed control for field crops, pastures, rangeland, and noncropland. Kansas State University Agricultural Experiment Station and Cooperative Extension Service. 1148.

Roeth, F., Martin, A., \& Klein, R.N., 1994. Shattercane and its control. University of Nebraska-Lincoln Extension. G94-1205 http://digitalcommons.unl.edu/extensionhist/ 1503

Rosales-Robles, E., J. M. Chandler, H. Wu, S. A. Senseman \& J. Salinas-Garcia. 2003. 
A model to predict the influence of temperature on rhizome johnsongrass (Sorghum halepense) development. Weed Sciencee 51:356-362.

Schmidt, J. J., J. F. Pedersen, M. L. Bernards, \& J. L. Lindquist. 2013. Rate of shattercane x sorghum hybridization in situ. Crop Science. 53, 1677-1685.

Stoller, E. W. 1977. Differential cold tolerance of quackgrass and johnsongrass rhizomes. Weed Science 25:348-351.

Subramanian N, Lavy D, Sias C, Hodnett G, Rooney W, \& Bagavathiannan M (2020) Understanding gene flow from grain sorghum (Sorghum bicolor) to johnsongrass (S. halepense). In: Proceedings of the Weed Science Society of America Annual Meeting, Maui, HI.

Taylorson, R. B. \& C. G. McWhorter. 1969. Seed dormancy and germination in ecotypes of johnsongrass. Weed Science 17:359-361.

Venable, D. L. 1989. Modeling the evolutionary ecology of seed banks. Pages 67-90 in M. A. Leck, V. T. Parker, and R. L. Simpson, eds. Ecology of soil seed banks. Academic Press, New York.

Warwick, S. I. \& L. D. Black. 1983. The biology of Canadian weeds. 61. Sorghum halepense (L.) Pers. Canadian Journal of Plant Science 63:997-1014.

Warwick, S. I. D. Phillips \& C. Andrews. 1986. Rhizome depth: the critical factor in winter survival of Sorghum halepense (L.) Pers. (Johnson grass). Weed Research 26:381387 
Werle, R., B. Tenhumberg \& J. L. Lindquist. 2017. Modeling shattercane dynamics in herbicide-tolerant grain sorghum cropping systems. Ecological Modelling 343:131141. 
Table S1: Johnsongrass Model Parameters. MD refers to the maximum density of culms from seedlings and sprouts per $m^{-2}$; Comp indicates to the relative competitive ability of seedlings and sprouts

\begin{tabular}{|c|c|c|c|c|}
\hline Vital Rate & & Symbol & Time & Value \\
\hline \multirow{2}{*}{\multicolumn{2}{|c|}{ Seed Survival }} & $s_{1 J}$ & June-Oct & 0.70 \\
\hline & & $s_{1 N}$ & Nov-March & 0.25 \\
\hline \multirow[t]{2}{*}{ (Seed predation before entering seed bank) } & & $s_{1 P}$ & & 0.35 \\
\hline & & $s_{1 A}$ & April-May & 0.97 \\
\hline \multirow{4}{*}{$\begin{array}{l}\text { Bud Survival } \\
(1-\text { year old buds }) \\
(2-\text { year old buds })\end{array}$} & & $s_{2 J}$ & June-Oct & 0.50 \\
\hline & & $s_{2 N_{1}}$ & Nov-March & 0.50 \\
\hline & & $s_{2 \mathrm{~N}_{2}}$ & Nov-March & 0.10 \\
\hline & & $s_{2 A}$ & April-May & 0.98 \\
\hline \multirow{4}{*}{$\begin{array}{l}\text { Seedling Survival } \\
\text { Seedling Survival (self-thinning, Eq.4) }\end{array}$} & & $s_{3 J}$ & June-Flowering & 0.90 \\
\hline & & $s_{3 A}$ & April-May & $\mathrm{DD}^{*}$ \\
\hline & MD & $\alpha_{3 A}$ & & 0.008 \\
\hline & Comp & $\delta_{3 A}$ & & 2.0 \\
\hline \multirow{4}{*}{$\begin{array}{l}\text { Sprout Survival } \\
\text { Sprout Survival (self-thinning, Eq.4) }\end{array}$} & & $s_{4 J}$ & June-Flowering & 0.95 \\
\hline & & $s_{4 A}$ & April-May & $\mathrm{DD}^{*}$ \\
\hline & MD & $\alpha_{4 A}$ & & 0.008 \\
\hline & Comp & $\delta_{4 \mathrm{~A}}$ & & 0.5 \\
\hline Seed Germination & & $\tilde{g}_{1}$ & & 0.35 \\
\hline Bud Sprouting & & $\tilde{g}_{2}$ & & 0.73 \\
\hline Probability of Gene Transfer & & $\gamma$ & & 0.0001 \\
\hline Dominance of Resistance Genes & & $h$ & & 7 \\
\hline
\end{tabular}

* Spring survival of culms from seedlings $\left(s_{3} A\right)$ and sprouts $\left(s_{4} A\right)$ are density dependent (Equation 4 in main text). 
Table S2: Parameter estimates for modeling density dependent reproduction of Johnsongrass (equation 6 in main text, number of seeds or buds per culm). The subscript $i$ specifies which plant stage reproduces (seedlings $O=3$, or sprouts $Q=4$ ); and subscript $j$ specifies the type of reproduction (seeds $S=1$, or buds $B=2$ ). So, $m_{i j}$ specifies maximum seed production per seedling culm $(i=3, j=1)$, maximum seed production per sprout culm $(i=4, j=1)$, maximum bud production per seedling culm $(i=3, j=2)$, and maximum bud production per sprout culm $(i=4, j=2)$

\begin{tabular}{llccr}
\hline \hline & Crop & Stage $i$ & Type $j$ & Value \\
\hline Max Reproduction/culm, $m_{i j}$ & & 3 & 1 & 200,000 \\
& & 4 & 1 & 280,000 \\
& & 3 & 2 & 4000 \\
& & 4 & 2 & 4800 \\
\hline Weed Competitiveness, $\kappa_{w}$ & & & & 0.00549 \\
Crop Competitiveness, $\kappa_{c}$ & & & 0.029 \\
\hline Crop Density, $d_{c}$ & Inzen & & & 10 \\
$\left(\right.$ culms $\left.m^{2}\right)$ & Sorghum & & & 10 \\
& Soybean & & & 33 \\
& Wheat & & & 100 \\
\hline & Non-Crop & & & \\
\hline
\end{tabular}


Table S3: Johnsongrass survival of herbicide applications depending on the crop species planted. $O$ are seedlings, $Q$ are sprouts, and $B$ are buds in the bud bank. For Inzen, the table provides the survival of two Johnsongrass genotypes, where " $R$ " indicates a resistance allele and " $r$ " a susceptible allele. The survival of the other Inzen genotypes depends on the number of resistance alleles and the degree of dominance (see equations $1 \& 2$ in the main text). Since we assume complete dominance of the resistance traits the genotypes $R R R R, r R R R, \operatorname{rr} R R$, and $\operatorname{rrr} R$ have the same probability of surviving ALS applications. Herb indicates the type of herbicides used (Gly = glyphosate; ALS = nicosulfuron, $\mathrm{C}=$ clethodim), PRE and POST indicates whether the herbicide is sprayed before or after the emergence of the crop. Total specifies the survival of PRE+POST herbicide application. Surv indicated the survival probability and Var is the variance in total survival probability.

\begin{tabular}{|c|c|c|c|c|c|c|c|c|c|}
\hline \multirow[t]{2}{*}{ Crop } & \multicolumn{3}{|c|}{ PRE } & \multicolumn{3}{|c|}{ POST } & \multicolumn{3}{|c|}{ Total } \\
\hline & Herb & Stage & Surv & Herb & Stage & Surv & Stage & Surv & Var \\
\hline $\begin{array}{l}\text { Inzen sorghum } \\
(\text { rrrr })\end{array}$ & Gly & $\begin{array}{l}O+Q \\
B\end{array}$ & $\begin{array}{l}0.4 \\
0.4\end{array}$ & ALS & $\begin{array}{l}O+Q \\
B\end{array}$ & $\begin{array}{l}0.025 \\
0.1\end{array}$ & $\begin{array}{l}O+Q \\
B\end{array}$ & $\begin{array}{l}0.01 \\
0.04\end{array}$ & $\begin{array}{l}0.0025 \\
0.01\end{array}$ \\
\hline $\begin{array}{l}\text { Inzen sorghum } \\
(R R R R, r R R R \\
r r R R, r r r R)\end{array}$ & Gly & $\begin{array}{l}O+Q \\
B\end{array}$ & $\begin{array}{l}0.4 \\
0.4\end{array}$ & ALS & $\begin{array}{l}O+Q \\
B\end{array}$ & $\begin{array}{l}1 \\
1\end{array}$ & $\begin{array}{l}O+Q \\
B\end{array}$ & $\begin{array}{l}0.4 \\
0.4\end{array}$ & $\begin{array}{l}0.09 \\
0.09\end{array}$ \\
\hline $\begin{array}{l}\text { Conventional } \\
\text { sorghum }\end{array}$ & Gly & $\begin{array}{l}O+Q \\
B\end{array}$ & $\begin{array}{l}0.4 \\
0.4\end{array}$ & & & & $\begin{array}{l}O+Q \\
B\end{array}$ & $\begin{array}{l}0.4 \\
0.4\end{array}$ & $\begin{array}{l}0.04 \\
0.04\end{array}$ \\
\hline Soybean & & & & $\mathrm{Gly}+\mathrm{C}$ & $\begin{array}{l}O+Q \\
B\end{array}$ & $\begin{array}{l}0.01 \\
0.05\end{array}$ & $\begin{array}{l}O+Q \\
B\end{array}$ & $\begin{array}{l}0.01 \\
0.05\end{array}$ & $\begin{array}{l}0.001 \\
0.005\end{array}$ \\
\hline Wheat & & & & Gly & $\begin{array}{l}O+Q \\
B\end{array}$ & $\begin{array}{l}0.005 \\
0.02\end{array}$ & $\begin{array}{l}O+Q \\
B\end{array}$ & $\begin{array}{l}0.005 \\
0.02\end{array}$ & $\begin{array}{l}0.0005 \\
0.002\end{array}$ \\
\hline Non-Crop & Gly & $\begin{array}{l}O+Q \\
B\end{array}$ & $\begin{array}{l}0.005 \\
0.01\end{array}$ & & & & $\begin{array}{l}O+Q \\
B\end{array}$ & $\begin{array}{l}0.005 \\
0.01\end{array}$ & $\begin{array}{l}0.0005 \\
0.001\end{array}$ \\
\hline
\end{tabular}


Supporting Information. Holmes, K. H., Lindquist, J.L., Rebarber, R., Werle, R., Yerka, M., and Tenhumberg, B. Modeling the evolution of herbicide resistance in weed species with a complex life cycle. Ecological Applications.

Appendix S2 

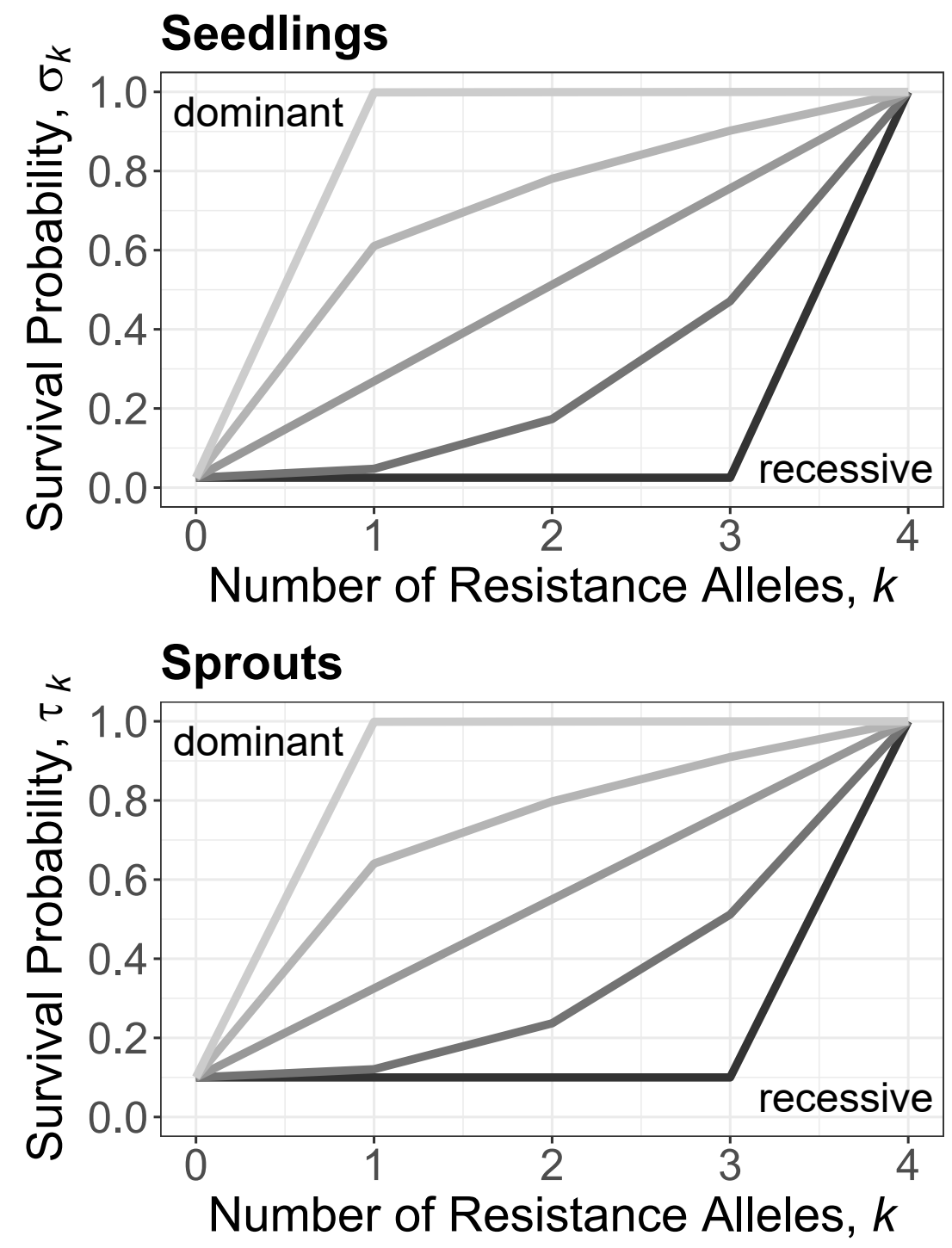

Figure S1: Effect of the degree of dominance $(h)$ on the probability of seedlings and sprouts surviving herbicide application of genotypes with $k$ number of resistance alleles. The lighter the lines the the larger the $h$-value $(h=-7,1,0,1,7)$ 
Supporting Information. Holmes, K. H., Lindquist, J.L., Rebarber, R., Werle, R., Yerka, M., and Tenhumberg, B. Modeling the evolution of herbicide resistance in weed species with a complex life cycle. Ecological Applications.

Appendix S3 


\section{Implementing Germination and Sprouting}

The probability of seeds germinating is $\tilde{g}_{1}$, and the probability of buds sprouting is $\tilde{g}_{2}$. Because winter and spring survival terms are always multiplied by the probability of a seed germinating or a bud sprouting, the following simplifications can be made:

$$
\begin{array}{ll}
g_{1}:=s_{1 N} \tilde{g}_{1} s_{3 A}, & \hat{g}_{1}:=s_{1 N}\left(1-\tilde{g}_{1}\right) s_{1 A}, \\
g_{2_{1}}:=s_{2 N_{1}} \tilde{g}_{2} s_{4 A}, & \hat{g}_{21}:=s_{2 N_{1}}\left(1-\tilde{g}_{2}\right) s_{2 A}, \\
g_{2_{2}}:=s_{2 N_{2}} g_{2} s_{4 A} & \hat{g}_{2_{2}}:=s_{2 N_{2}}\left(1-g_{2}\right) s_{2 A} .
\end{array}
$$


Supporting Information. Holmes, K. H., Lindquist, J.L., Rebarber, R., Werle, R., Yerka, M., and Tenhumberg, B. Modeling the evolution of herbicide resistance in weed species with a complex life cycle. Ecological Applications.

Appendix S4 


\section{Supplementary Equations}

We underline all symbols representing a matrix of size $(n+1) \times(n+1)(5 \times 5$ in our tetraploid model), to avoid confusion. Let $\underline{I}$ be the $(n+1) \times(n+1)$ identity matrix and $\underline{0}$ be the $(n+1) \times(n+1)$ matrix containing all zeros. Further, let

$$
\underline{1}=\left[\begin{array}{cccc}
1 & 1 & \cdots & 1 \\
0 & 0 & \ldots & 0 \\
\vdots & & \ddots & \vdots \\
0 & 0 & \ldots & 0
\end{array}\right]
$$

of size $(n+1) \times(n+1)$ and

$$
\underline{h}=\left[\begin{array}{cccc}
(\tilde{p}(t+1))^{n} & 0 & \ldots & 0 \\
n(\tilde{p}(t+1))^{n-1}(1-\tilde{p}(t+1)) & 0 & \ldots & 0 \\
\vdots & & \ddots & \vdots \\
(1-\tilde{p}(t+1))^{n} & 0 & \ldots & 0
\end{array}\right],
$$

Hardy-Weinberg ratios for $n$-ploid populations, each of size $(n+1) \times(n+1)$ (found 
using binomial expansion). For an example, our tetraploid model would have

$$
\underline{h}=\left[\begin{array}{ccccc}
(\tilde{p}(t+1))^{4} & 0 & 0 & 0 & 0 \\
4(\tilde{p}(t+1))^{3}(1-\tilde{p}(t+1)) & 0 & 0 & 0 & 0 \\
6(\tilde{p}(t+1))^{2}(1-\tilde{p}(t+1))^{2} & 0 & 0 & 0 & 0 \\
4(\tilde{p}(t+1))(1-\tilde{p}(t+1))^{3} & 0 & 0 & 0 & 0 \\
(1-\tilde{p}(t+1))^{4} & 0 & 0 & 0 & 0
\end{array}\right] .
$$

We use the following matrices to describe the effects of $\mu, \sigma$ and $\tau$.

$$
\underline{A_{1}}(t)=\left[\begin{array}{cccc}
\tau_{n} & 0 & \cdots & 0 \\
0 & \tau_{n-1} & & 0 \\
\vdots & & \ddots & 0 \\
0 & 0 & 0 & \tau_{0}
\end{array}\right], \underline{A_{2}}(t)=\left[\begin{array}{cccc}
\sigma_{n} & 0 & \cdots & 0 \\
0 & \sigma_{n-1} & & 0 \\
\vdots & & \ddots & 0 \\
0 & 0 & 0 & \sigma_{0}
\end{array}\right], \text { and } \underline{A_{3}}=\left[\begin{array}{cccc}
\mu_{n} & 0 & \cdots & 0 \\
0 & \mu_{n-1} & & 0 \\
\vdots & & \ddots & 0 \\
0 & 0 & 0 & \mu_{0}
\end{array}\right],
$$

Recall the following population vector of length $4(n+1)$ (length 20 in our tetraploid model):

$$
\mathbf{w}(t)=\left[S_{n}, S_{n-1}, \ldots, S_{0}, B_{n}, B_{n-1}, \ldots, B_{0}, O_{n}, O_{n-1}, \ldots, O_{0}, Q_{n}, Q_{n-1}, \ldots, Q_{0}\right]
$$

Finally, we let

$$
\mathbf{w}(t+1)=G_{1} F_{1}(t) M_{1}(t) \mathbf{w}(t)+G_{2} H(t) W F_{2}(t) M_{2}(t) \mathbf{w}(t),
$$


with the following $4(n+1) \times 4(n+1)$ matrices $(20 \times 20$ in our tetraploid model):

$$
\begin{gathered}
M_{1}(t)=\left[\begin{array}{cccc}
s_{1 J} \underline{I} & \underline{0} & \underline{0} & \underline{0} \\
\underline{0} & s_{2 J} \underline{A_{1}}(t) & \underline{0} & \underline{0} \\
\underline{0} & \underline{0} & s_{3 J} \underline{A_{2}}(t) & \underline{0} \\
\underline{0} & \underline{0} & \underline{0} & s_{4 J} \underline{A_{2}}(t)
\end{array}\right], \\
M_{2}(t)=\left[\begin{array}{llll}
\underline{0} & \underline{0} & \underline{0} & \underline{0} \\
\underline{0} & \underline{0} & \underline{0} & \underline{0} \\
\underline{0} & \underline{0} & s_{3 J} \underline{A_{2}}(t) & \underline{0} \\
\underline{0} & \underline{0} & \underline{0} & s_{4 J} \underline{A_{2}}(t)
\end{array}\right],
\end{gathered}
$$

where $M_{1}$ and $M_{2}$ represent the summer mortality for vegetative and seed-based contributions to the population respectively. Likewise, for the following two matrices, $F_{1}$ and $F_{2}$ represent fecundity for the vegetative and seed based contributions to the population:

$$
\begin{gathered}
F_{1}(t)=\left[\begin{array}{cccc}
\underline{I} & \underline{0} & \underline{0} & \underline{0} \\
\underline{0} & \underline{I} & \underline{0} & \underline{0} \\
\underline{0} & \underline{0} & s_{1 P} f_{3,2}(t) \underline{I} & \underline{0} \\
\underline{0} & \underline{0} & \underline{0} & s_{1 P} f_{4,2}(t) \underline{I}
\end{array}\right], \\
F_{2}(t)=\left[\begin{array}{llcc}
\underline{I} & \underline{0} & \underline{0} & \underline{0} \\
\underline{0} & \underline{I} & \underline{0} & \underline{0} \\
\underline{0} & \underline{0} & f_{3,1}(t) \underline{A_{3}} & \underline{0} \\
\underline{0} & \underline{0} & \underline{0} & f_{4,1}(t) \underline{A_{3}}
\end{array}\right] .
\end{gathered}
$$


The matrix, $W$ is used to collect the newly produced seeds, which are then sorted into appropriate Hardy-Weinberg-Ratios using $H(t)$ :

$$
\begin{gathered}
W=\left[\begin{array}{llll}
\underline{0} & \underline{0} & \underline{0} & \underline{0} \\
\underline{0} & \underline{0} & \underline{0} & \underline{0} \\
\underline{0} & \underline{0} & \underline{1} & \underline{0} \\
\underline{0} & \underline{0} & \underline{0} & \underline{1}
\end{array}\right], \\
H(t)=\left[\begin{array}{llll}
\underline{0} & \underline{0} & \underline{0} & \underline{0} \\
\underline{0} & \underline{0} & \underline{0} & \underline{0} \\
\underline{0} & \underline{0} & \underline{h} & \underline{0} \\
\underline{0} & \underline{0} & \underline{0} & \underline{h}
\end{array}\right] .
\end{gathered}
$$

Finally, $G_{1}$ and $G_{2}$ contain the remaining vital rates post-fecundity, for vegetative and seed-based contributions to the population:

$$
G_{1}=\left[\begin{array}{cccc}
\hat{g}_{1} \underline{I} & \underline{0} & \underline{0} & \underline{0} \\
\underline{0} & \hat{g}_{2_{2}} \underline{I} & \hat{g}_{2_{1}} \underline{I} & \hat{g}_{2_{1}} \underline{I} \\
g_{1} \underline{I} & \underline{0} & \underline{0} & \underline{0} \\
\underline{0} & g_{2_{2}} \underline{I} & g_{2_{1}} \underline{I} & g_{2_{1}} \underline{I}
\end{array}\right],
$$




$$
G_{2}=\left[\begin{array}{cccc}
\underline{0} & \underline{0} & \hat{g}_{1} \underline{I} & \hat{g}_{1} \underline{I} \\
\underline{0} & \underline{0} & \underline{0} & \underline{0} \\
\underline{0} & \underline{0} & g_{1} \underline{I} & g_{1} \underline{I} \\
\underline{0} & \underline{0} & \underline{0} & \underline{0}
\end{array}\right] .
$$


Supporting Information. Holmes, K. H., Lindquist, J.L., Rebarber, R., Werle, R., Yerka, M., and Tenhumberg, B. Modeling the evolution of herbicide resistance in weed species with a complex life cycle. Ecological Applications.

Appendix S5 

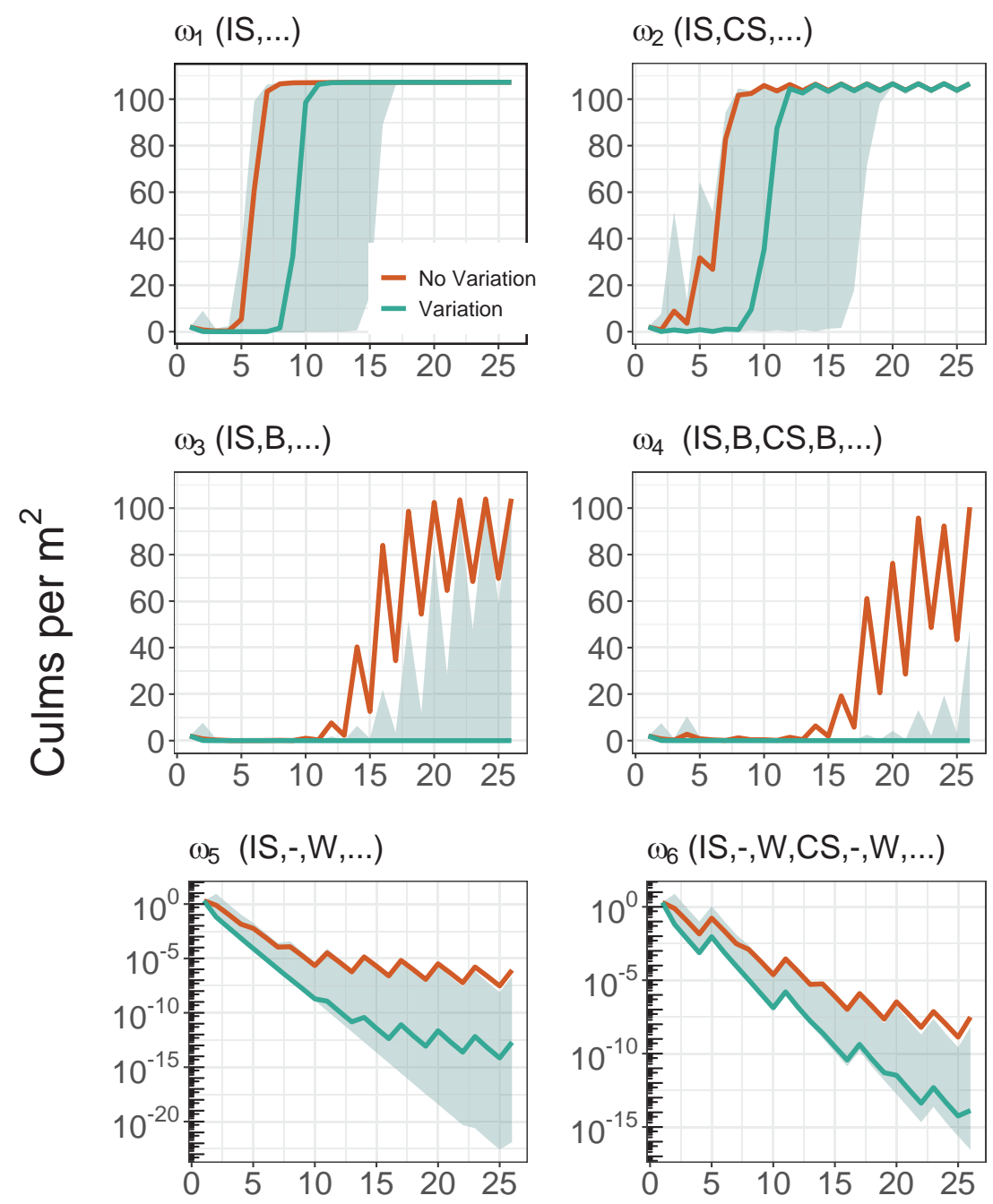

Time (years)

Figure S1: Population dynamics for the stochastic model for different crop rotations. We assume that initially $(t=0)$ the population has a frequency of the resistance allele $\rho=$ 0 . The solid orange line represents the deterministic model, the solid green line represents the median of 10,000 stochastic trials, while the shaded area represents $95 \%$ confidence intervals for the stochastic model. Note that the bottom graphs $\left(\omega_{4}\right.$ and $\left.\omega_{5}\right)$ are scaled differently from the rest. IS = Inzen sorghum; CS = conventional sorghum; B = soybean; - = no crop ; $\mathrm{W}=$ wheat. 

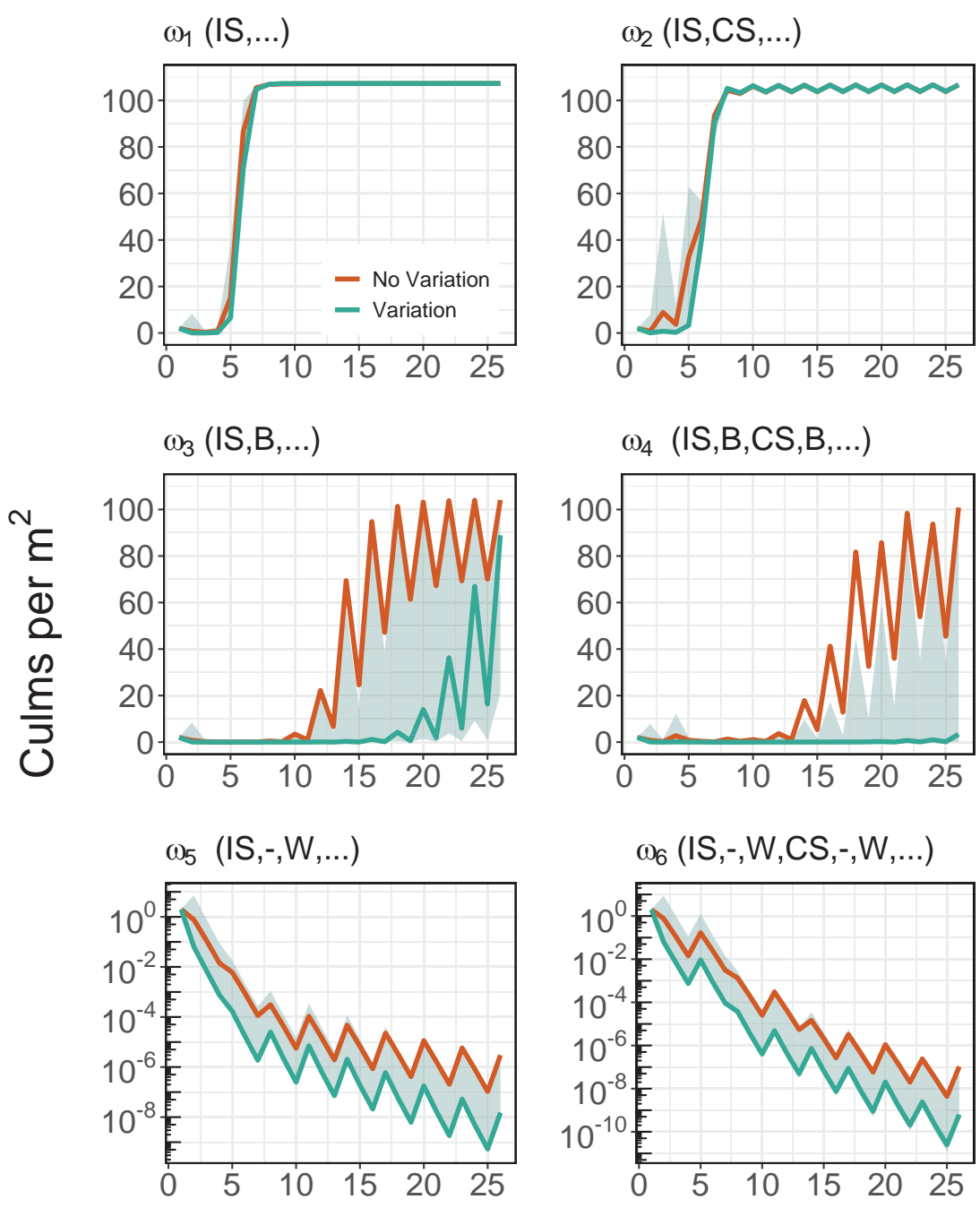

Time (years)

Figure S2: Population dynamics for the stochastic model for different crop rotations. We assume that initially $(t=0)$ the population has a frequency of the resistance allele $\rho=0.0006$. The solid orange line represents the deterministic model, the solid green line represents the median of 10,000 stochastic trials, while the shaded area represents $95 \%$ confidence intervals for the stochastic model. Note that the bottom graphs $\left(\omega_{4}\right.$ and $\left.\omega_{5}\right)$ are scaled differently from the rest. IS = Inzen sorghum; CS = conventional sorghum; B = soybean; $-=$ no crop ; $\mathrm{W}=$ wheat. 